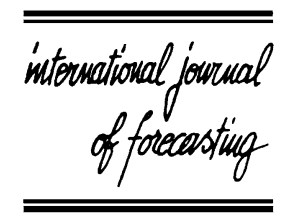

www.elsevier.com/locate/ijforecast

\author{
Review
}

\title{
Demographic forecasting: 1980 to 2005 in review
}

\author{
Heather Booth * \\ Demography and Sociology Program, Research School of Social Sciences, Australian National University, \\ Canberra ACT 0200, Australia
}

\begin{abstract}
Approaches and developments in demographic and population forecasting since 1980 are reviewed. Three approaches to forecasting demographic processes are extrapolation, expectation (individual-level birth expectations or population-level opinions of experts), and theory-based structural modelling involving exogenous variables. Models include 0-3 factors (age, period and cohort). Decomposition and disaggregation are also used in multistate models, including macrosimulation and microsimulation. Forecasting demographic change is difficult; accuracy depends on the particular situation or trends, but it is not clear when a method will perform best. Estimates of uncertainty (model-based ex ante error, expert-opinion-based ex ante error, and ex post error) differ; uncertainty estimation is highly uncertain. Probabilistic population forecasts are based on stochastic population renewal or random scenarios. The approaches to population forecasting, demographic process forecasting and error estimation are closely linked. Complementary methods that combine approaches are increasingly employed. The paper summarises developments, assesses progress and considers the future.
\end{abstract}

(C) 2006 International Institute of Forecasters. Published by Elsevier B.V. All rights reserved.

Keywords: Demographic modelling; Population forecasting; Mortality; Fertility; Migration; Extrapolation; Expectations; Causal models; Disaggregation

\section{Contents}

1. Introduction . . . . . . . . . . . . . . . . . . . . . . . . . . . 548

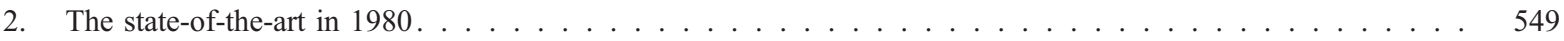

3. Approaches to forecasting the demographic components . . . . . . . . . . . . . . . . . . . . 550

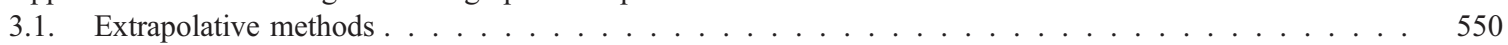

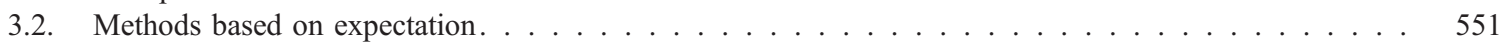

3.3. Structural modelling . . . . . . . . . . . . . . . . . . . . . . . . . 552

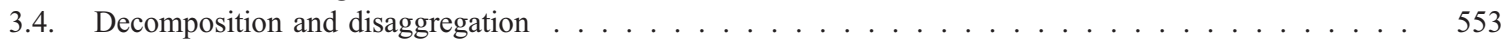

3.5. Choice of approach . . . . . . . . . . . . . . . . . . . . . . . . 553

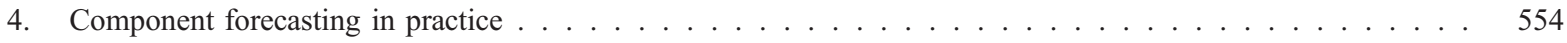

\footnotetext{
* Tel.: +61 26125 4062; fax: +61261253031.

E-mail address: heather.booth@anu.edu.au.
}

0169-2070/\$ - see front matter (C) 2006 International Institute of Forecasters. Published by Elsevier B.V. All rights reserved. 


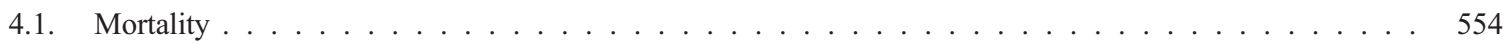

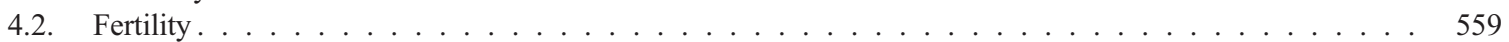

4.3. Migration. . . . . . . . . . . . . . . . . . . . . . . . . 562

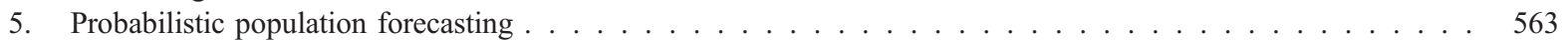

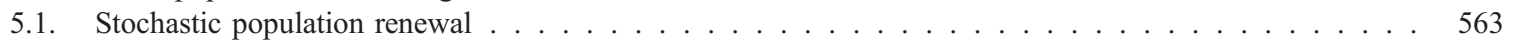

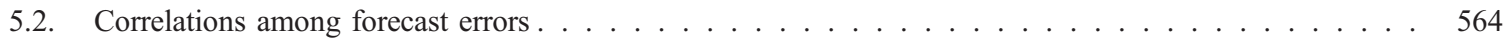

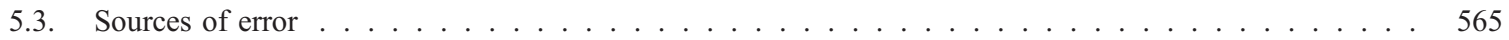

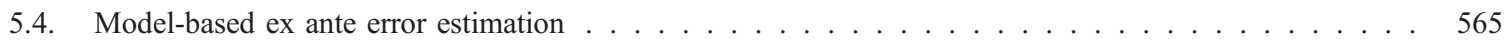

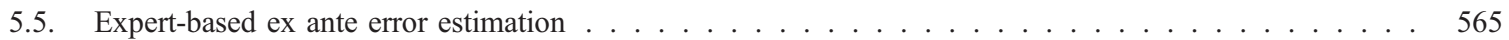

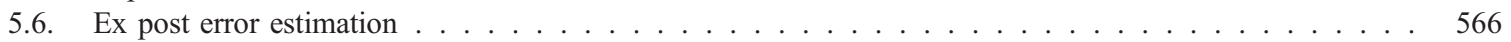

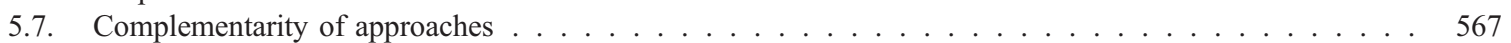

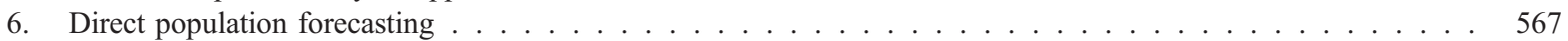

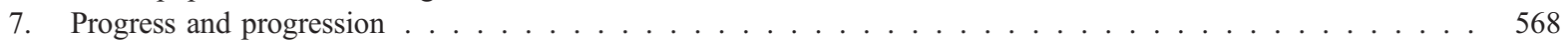

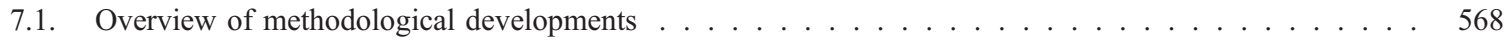

7.2. Progress in forecasting performance . . . . . . . . . . . . . . . . . . . . 569

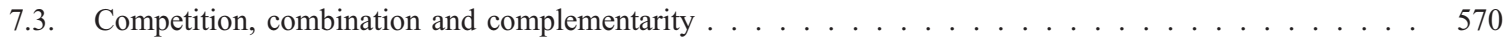

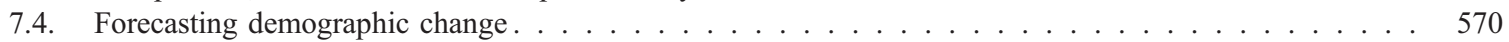

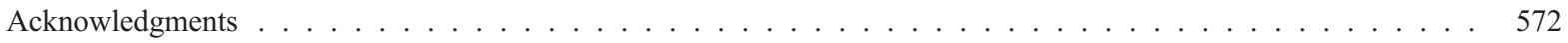

References . . . . . . . . . . . . . . . . . . . . . . . . . . . . 572

\section{Introduction}

The last twenty-five years has been an exciting period in the history of demographic forecasting. It has witnessed the emergence from a period of relative inactivity, the realisation of previously unappreciated truths about traditional methods of population projection and the development of new probabilistic approaches to the problem. This heightened activity does not seem to be a result of more demanding users; rather it appears that demographers are adopting the methods of other disciplines and applying them to their trade. Perhaps, in a world of increasing statistical sophistication, the discipline could no longer afford to have population forecasting regarded as "an oldfashioned art form, somewhat embarrassing to the profession, like a disreputable relative" (Ryder, 1990:433). Population forecasting is, after all, the public face of the profession.

Demographic forecasting is an important topic: population, household and related forecasts form the basis of social and economic planning and are fundamental to many other forecasting exercises. The many uses of population forecasts give rise to choices on several dimensions. The time horizon may be as short as a year, more commonly a generation, increasingly a life span, or occasionally longer still.
The population in question may be local, national, regional or global. To provide the necessary detail, the population must be disaggregated by age and sex, and often by geographical region; yet further disaggregation may be desired. To achieve this, the three components of population change (mortality, fertility and migration) must be separately forecast and appropriately combined; each component may be decomposed and its parts independently forecast. Population forecasting is thus a highly complex and difficult undertaking (Keyfitz, 1985).

Population forecasting is also highly uncertain: as Keyfitz (1996:xii) remarked, "The best demographers do it, but none would stake their reputation on the agreement of their forecasts with the subsequent realization." Uncertainty in demographic forecasting has been a major focus, contributing to the rapidly increasing volume of published research on the overall topic. It is impossible to include all this material in a single review. Several useful collections and studies have previously appeared (notably Ahlburg \& Land, 1992a; Bongaarts \& Bulatao, 2000; Lutz \& Goldstein, 2004a; Lutz, Vaupel, \& Ahlburg, 1999; North American Actuarial Journal, 1999; Rogers, 1995a).

During the twentieth century, fertility was the most important component in determining population size. 
However, forecasting fertility proved to be difficult in the post-World War II era: neither the "baby booms" of the 1950s nor the "baby busts" of the 1970s were foreseen. Neither was the post-war rapid decline in mortality foreseen. Both mortality and migration forecasting were naïve: for decades, official population forecasts widely assumed that mortality would not improve, at least beyond the immediate future, and migration was treated as an uninteresting constant.

The historical booms and busts in childbearing have to a large degree provided the impetus for the more recent renewal of interest in demographic forecasting. The uneven and transitionary age structure created by past fertility fluctuations is the dominant feature of present day demography in the developed world. Populations are ageing: not only is the large cohort of baby boomers moving into the post-retirement ages, but the baby-bust and younger cohorts are relatively small, creating fiscal problems for social security and health care provision for the elderly. In this context, forecasting mortality has gained prominence, fuelled by the fact that larger proportions will survive to older ages as life expectancy continues to rise. Further, replacement migration, seen as a solution to population ageing (United Nations, 2001), has increased the quantum of migration. In some countries, population growth due to migration now rivals natural increase, a clear indication that forecasting methods are needed for migration, notwithstanding the difficulties involved.

This paper reviews methodological developments in demographic forecasting during the last twenty-five years. It concentrates on forecasting the three components of population change and their combination in population forecasting, where applications are most common. The focus is on national forecasts, principally for industrialised countries where data availability permits greater statistical sophistication and where most research has been undertaken.

The paper is organised as follows. Section 2 briefly describes the state of the art of demographic forecasting that existed in 1980. Section 3 discusses approaches used in forecasting the demographic components. With this framework established, developments in modelling and forecasting mortality, fertility and migration are presented in Section 4. The combination of the components in probabilistic population forecasting is discussed in Section 5. The direct forecasting of populations is addressed in Section 6. Finally, Section 7 assesses progress and considers possible future developments.

\section{The state-of-the-art in $\mathbf{1 9 8 0}$}

Demographic forecasting has a long history (De Gans, 1999). By 1980 there was a well-established tradition of using the cohort-component method of population projection. This is a system of demographic accounting in which the population is advanced forward in time through the application of timespecific survivorship ratios by age and sex and the derivation of births from time-specific fertility rates of women by age; migration by age and sex can also be incorporated (Preston, Heuveline, \& Guillot, 2001: 119-129). The problem of population projection is thus decomposed into the separate forecasting of these three components of population change.

Traditional population projections typically comprise three deterministic scenarios, based on combinations of assumptions about mortality, fertility and migration. If mortality, fertility and migration each have three alternative assumptions or variants, there are nine possible combinations from which three are chosen as the high, medium and low scenarios according to population size. Often the components are restricted to one or two variants; indeed, the difference between scenarios may be entirely due to one component (usually fertility). However derived, the high-low interval is generally portrayed as containing likely future population values.

A limitation of this scenario-based approach is that it is impossible to specify the probability for the highlow interval, even if probabilities could be specified for the range in component variants. Further, the assumptions embody an element of rigidity: component variants are typically high, medium or low for the duration of the forecast rather than varying within the range over time. Perfect correlations are also introduced across age by the use of fixed age patterns, and between components by the particular component combination for each scenario. These correlations result in the probabilistic inconsistency of population projections: the high-low interval for population size will be inconsistent with high-low intervals for other characteristics of the projected population, notably 
ratios of age groups (Alho \& Spencer, 1985; Lee \& Tuljapurkar, 1994).

Both the patent inability of demographers to foresee demographic change and the rigidity of the scenario-based approach contributed to the assertion that traditional population projections are merely 'what-if' illustrations. Increasingly, however, demographers (e.g., Ahlburg \& Lutz, 1999; Ahlburg \& Vaupel, 1990; Stoto, 1983) regard any so-called projection intended to be a best guess of the future as a forecast, and this is the view taken here. Certainly users adopt this view: as Keyfitz (1972:353) remarked, "a demographer makes a projection, and his reader uses it as a forecast".

In 1980, this traditional deterministic scenariobased approach was used by international bodies, such as the United Nations (UN) and World Bank, and national statistical offices almost without exception. Today, changes are occurring: statistical forecasting is gaining prominence. The developments that have led to these changes are reviewed in the following sections. The ongoing use of the traditional approach is not discussed.

\section{Approaches to forecasting the demographic components}

In forecasting demographic processes such as mortality, fertility and migration, three approaches or classes of methods are often identified: extrapolation, expectation and explanation. Extrapolative methods focus on the regularity of patterns and trends and extend these into the future without recourse to other knowledge in the form of exogenous variables. Methods based on expectation may use individual data (such as surveys of women's future birth expectations) or the opinions of experts about future demographic developments. Methods seeking to explain demographic processes use structural models based on theories relating demographic quantities to other variables.

In practice, the distinction between methods is not always clear-cut. Subjective expert opinion may be incorporated into extrapolative methods, exogenous variables are sometimes used to enhance extrapolative models, and structural models may involve extrapolation. A method may also be used in conjunction with decomposition and disaggregation. Disaggregation of the population serves to account for variation in the demographic process, while decomposition of the process simplifies this task and increases understanding. This 'explanatory' approach may be viewed as an alternative to causal structural modelling.

To some extent, the forecasting approach is linked to the measure used: events or rates (or probabilities), aggregate or age-specific, period or cohort. A major problem for age-specific forecasting is high dimensionality, especially when single years of age are used. Parametric models are widely used to address this problem.

The models used in forecasting can be classified according to the number of factors modelled: zero, one, two or three (following Tabeau, 2001). A factor may be viewed as a classificatory variable intrinsic to the data. Zero-factor models are simply the time series of aggregate measures or age-specific rates (each treated independently). One-factor models express demographic rates as a function of age (or duration), making use of their characteristic and stable age patterns. Two-factor models most commonly take age (duration) and period (time) into account; they may model age and cohort but cohort models demand lengthy series of annual data. Threefactor or age-period-cohort (APC) models aim to distinguish between age, period and cohort effects, but suffer from the identification problem arising from the linear dependence of any one factor on the remaining two (see Tabeau, 2001). If three-way classification (also known as doubly-classified data or non-overlapping cohorts) is used in data collection, this dependence is lost (Willekens \& Baydar, 1986). The APC model is useful in describing the past but has not generally been successful in forecasting. The more complex models are used predominantly in extrapolation.

\subsection{Extrapolative methods}

Extrapolation is the most common approach in demographic forecasting. Extrapolative methods are essentially atheoretical; the only assumption is that the future will be (in some sense) a continuation of the past. This is their strength, but it is also their fundamental weakness: historical patterns may not be the best guide to the future, notably because 
changes in the trend, or structural changes, may be missed. Extrapolative methods make no use of exogenous variables: they do not incorporate current knowledge about actual and prospective developments in relevant areas such as medicine and new diseases, lifestyles and the economy.

The most commonly-used method of extrapolation is univariate ARIMA modelling (Box \& Jenkins, 1976). In the case of zero-factor models, such as a time series of total births, the series is directly modelled and forecast. When one-factor models are employed, the time series are the fitted parameters of the deterministic model (a parameterisation function or relational model). Erratic parameter time series and interdependencies among parameters present difficulties for forecasting. Forecast age patterns may be implausible, and if interdependencies are not taken into account (e.g., by a vector autoregression), forecast prediction intervals will be inaccurate.

Principal component models are multiplicative two-factor models used with time series extrapolation in forecasting. The estimated age parameters (or functions) are assumed to be fixed and time series methods are used to extrapolate the time-varying parameters. The most prominent example is the LeeCarter model (Lee \& Carter, 1992). Tabeau (2001) noted that the Lee-Carter model can be viewed as a statistical association model for a two-way crossclassification table, and as such belongs to the class of generalised linear modelling (GLM) and can be estimated by maximum likelihood estimation for Poisson-distributed errors. This link was first used by Wilmoth (1993) and has been developed by others.

An alternative approach to time series methods is to directly model demographic rates within the GLM framework with time as an explicit covariate. The zero-factor model is a constant and the one-factor model is a simple regression on time. Additive bivariate regression models constitute the two-factor case. An extension is the dynamic parameterisation model (Tabeau, Ekamper, Huisman, \& Bosch, 2001) in which the parameters of an initial static base parameterisation function are linear or non-linear functions of time. Since time is a covariate, forecasting is achieved by using appropriate time values. However, two- or higher-degree polynomials in time are often required to attain a satisfactory fit, leading to implausible forecasts. A partial solution is to use linear splines for subperiods, but this is restricted to short-term forecasting because turning points cannot be identified (De Beer, 1989).

\subsection{Methods based on expectation}

Methods based on expectation include the use of data on the expectations of individuals about their own behaviour, the use of data on the expectations of a group of experts about population-level behaviour based on historical data and research, and the less structured use of the expectations or informed judgment of experts in the forecasting process.

Demographic forecasting based on reported individual expectations is most common for fertility, where survey data on birth expectations are used (usually in a qualitative or ad hoc manner) to inform the forecast; however, the lead time is clearly limited. A problem with individual expectations data is that they tend to lag prevailing trends. Recent innovations in the collection of individual expectations data include direct questions about subjective probabilities of future events. For example, personal estimates of the chance of survival to a certain age produced similar survival probabilities to life table estimates (Hauser \& Willis, 2005). The approach may provide useful information for probabilistic forecasting, particularly where historical data are lacking.

Individual expectations can be viewed as the outcome of unspecified complex psycho-social models that determine individual decision-making (Hendershot \& Placek, 1981:307-310). In this sense, they are a substitute for the explicit theoretical models of structural modelling. Similarly, forecasts based on the expectations of a group of experts implicitly take theory into account (Lutz, 1996). The Delphi-based method developed by Lutz and colleagues (Lutz, Sanderson, Scherbov, \& Goujon, 1996) combines the qualitative and quantitative opinions of a group of experts into quantitative forecasts for each demographic component. The forecast is defined by three points in the future, thus allowing for limited changes in trend; linearity is assumed between points (see also Section 5.5).

The proponents of this expert-based approach argue that it is preferable to the time series approach because expert opinion takes into account the possi- 
bility of future structural change and unexpected events (Lutz, Goldstein, \& Prinz, 1996:38). However, the conservativeness of expert opinion with respect to mortality decline is widespread; Alho and Spencer (1990a) found that US experts systematically forecast smaller declines than actually occurred. Expert opinion about future fertility has not been any more accurate (Lee, 1999). Similar to the lag in individual expectation, expert opinion is subject to assumption drag (Ahlburg \& Vaupel, 1990). Further, the expertbased approach tends to be limited to aggregate measures, reflecting the difficulty in specifying such details as age-specific rates or parity-specific fertility, thereby precluding information that might be expected to be pertinent to identifying structural change. The approach is advantageous in developing countries because of its lesser demands for historical data.

Less formally, subjective judgment often influences the forecasts (Alders \& De Beer, 2005). Informed judgment may be directly involved in constraining or adjusting an extrapolative forecast through targeting, where the expert specifies a value of the relevant measure, the year by which it will be reached and by which path (Olshansky, 1988). Targets may be based on the experience of a more advanced population or subpopulation (Pollard, 1987), a model such as the UN 'ultimate life table' (United Nations, 2000), or notions of eventual stability as in replacement fertility (Lee, 1990). Linear interpolation, or a more complex curve fitting procedure such as assuming logistic growth, is then used between current and target rates. Targets tend to be limited to aggregate measures, while model life or fertility tables (e.g., United Nations, 2000) provide the target age pattern; intermediate values are derived through interpolation with respect to level. In the case of developing countries, the method is informed by demographic and epidemiological transition theories, or in the case of targets drawn from subpopulations, by heterogeneity theory (Olshansky, 1988).

Informed judgment has formed the basis of many assumptions in traditional population projections, either in combination with extrapolation or as the sole input. However, such methods have tended to be unsystematic and in many cases inadequately documented, even in developed countries (Cruijsen \& Eding, 2001; Lutz, Vaupel, \& Ahlburg, 1999; Olshansky, 1988).

\subsection{Structural modelling}

Structural models explain demographic rates in terms of the underlying socio-economic and proximate determinants. An advantage of structural feedback is that feedback mechanisms and limiting factors can be taken into account (Cohen, 1999; Lee, 1990). Unfortunately, the danger of model misspecification is high because of a less than secure theoretical basis: most if not all economic-demographic relationships are merely hypotheses (Ahlburg \& Land, 1992b). Further, high autocorrelations in the dependent and independent variable series produce high correlations between series, even when there is no causal link. In this situation, a model may have high descriptive power, but little predictive power. Nevertheless, assuming the underlying hypotheses hold, an important use of structural models is the simulation of the effect of policy changes affecting the independent variables.

Models based exclusively on lagged variables constitute a means of forecasting, but lag time limits the forecast horizon. In order to extend the forecast horizon, structural modelling is combined with extrapolation (e.g., using transfer function models). The focus of the forecasting problem is shifted from the demographic variable to its determinants. However, as Keyfitz (1982a) noted, it may be no less difficult to forecast the determinants than to directly forecast the variable. Brass (1974) set stringent conditions for which structural models can be useful for forecasting: the association between variables must persist over time, the exogenous variables must be predictable (or lagged), and the association must be strong. Land (1986:898) pointed to "what is essentially an impossibility theorem" for forecasting with structural models, namely Ashley's (1983) theorem that if the mean squared error of the forecast of the exogenous variable exceeds its variance, then including the forecasted exogenous variable will produce a worse forecast than omitting it. Unfortunately, the chances of the theorem applying increases with forecast length.

While forecasting with structural modelling is often regarded as the ideal, it has not on the whole produced more accurate forecasts. Keyfitz (1982a) concluded that knowledge has not improved the accuracy of forecasts. While Sanderson (1999) (and others, e.g., Heckman \& Walker, 1989) found 
evidence to the contrary, his conclusion was based on a comparison of several global and developingcountry structural models with scenario-based UN population projections. For developed countries, comparisons with other statistical forecasting methods are required. Nevertheless, the ideal of improved accuracy through structural modelling remains: Ahlburg, Lutz and Vaupel (1999:191) call for the greater use of models that include other demographic events (such as marriage and morbidity), that involve greater disaggregation (by education, for example) and that take into account economic, social and environmental dynamics. For reviews of aggregate economic-demographic models, see Land (1986) and Ahlburg (1987a). Sanderson (1999) reviews structural models used in global and developing country forecasts.

The theoretical advantage of structural modelling, the ability to capture turning points or structural change, has not often been realised. For fertility in particular, identifying changes in direction ahead of time has been a major difficulty. The demographers' inability to foresee the peaks and troughs of the postwar baby boom and bust is legendary. Ahlburg (1982) showed that the US Census Bureau failed to foresee all 20 turning points in 11 forecasts of total births (of 5-15 year durations from base years of 1948 to 1975). Structural models, notably models based on Easterlin's (1968) hypothesis of baby booms and busts, should in theory be better able to forecast structural change, but consistent success is elusive (Tuljapurkar \& Boe, 1999; Wachter, 1991).

\subsection{Decomposition and disaggregation}

Decomposition, such as the breakdown of mortality by cause of death or fertility by parity, is addressed by multiple-decrement life-table methods. The different parts may be best forecast by different methods. Disaggregation is the division of the base population beyond age and sex, for example, by education, ethnicity or region of residence. It is addressed by multistate modelling (Rogers, 1975, 1986, 1995b; Rogers \& Woodward, 1991), which is the dynamic multidimensional extension of the cohort-component model; transitions between states are modelled and demographic rates are specific to each state. Lutz, Goujon, and Doblhammer-Reiter (1999) discuss the criteria for useful disaggregation; the ideal is to find homogeneous subgroups (states) for which demographic rates are stable or changing in predictable ways so that extrapolation is appropriate. However, selection effects and unrecognised heterogeneity may limit the use of extrapolation (Vaupel \& Yashin, 1985).

Multistate modelling with many dimensions of disaggregation is macrosimulation. Individual-level disaggregation is microsimulation; at this finelydetailed level of disaggregation, accounting for variation is maximised and the probability of an event occurring is often assumed to be time-invariant. Microsimulation produces forecasts of both the numbers of persons in different states and the length of time spent in those states. Two important advantages of multistate modelling (particularly microsimulation) and its focus on transitions between states are the incorporation of behavioural feedbacks and the simulation of hypotheses for assessing the effect of behavioural change. The use of microsimulation models in probabilistic forecasting is reviewed by Van Imhoff and Post (1998), including a comparison with macrosimulation models.

\subsection{Choice of approach}

The choice of approach depends on various factors including data availability and purpose; judgment also plays an important role (Pollard, 1987). Land (1986) confounded approach and purpose in defining three classes of methods for forecasting national populations: demographic accounting or cohort-component methods for long-term population forecasting, statistical time series methods for short-term forecasts of demographic rates, and structural modelling methods for the simulation and forecasting of policy changes. For long-term forecasts, Land questioned the use of statistical time series methods and thus advocated the use of informed judgment and scenarios. More recently, time series methods have increasingly been used for long-term demographic forecasting with some apparent success, admittedly in stable circumstances. Willekens (1990:17) contends that the distinction between short- and long-term forecasting is a false issue: the real issue is when a method can be expected to be accurate — when the demographic system is stable or when it is changing. 
Whatever method is used for whatever period, it is important to draw the distinction between model fit and forecast accuracy. Ahlburg and Land (1992b) note that in-sample errors are not necessarily a good guide to forecast errors, and that for long-term forecasting the choice between models cannot reliably be based on historical goodness of fit. However, it is not clear which criteria should be used instead. Clearly there is a need for extensive analysis of out-of-sample or ex post forecast errors (see Section 5.6), but lengthy forecast horizons also limit the feasibility and usefulness of this approach. The measurement of forecast accuracy and the relevant loss function are related concerns (Ahlburg, 1995; Tayman \& Swanson, 1999; Tayman, Swanson, \& Barr, 1999).

Willekens (1990) noted the developmental path of forecasting in any discipline from the identification and extrapolation of stable patterns to an understanding of these patterns in terms of the causal mechanisms and processes involved: the search for regularity is transitionary. Rather than concentrate on improved methods of extrapolation, Willekens (1990:11) advocated research aimed at understanding the causal factors and processes involved as the precondition for effective forecasting. However, given the long-term nature of such a quest, he agreed with Keyfitz (1982a:747) that "we cannot afford to be ashamed of extrapolating the observed regularities of the past". This is as true today as it was then.

\section{Component forecasting in practice}

The framework established in Section 3 forms the organisational basis of the following discussion of developments during the last twenty-five years in modelling and forecasting mortality, fertility and migration. The direct forecasting of population is discussed in Section 6.

\subsection{Mortality}

Mortality forecasting has received a great deal of attention. Previous reviews include Keyfitz, (1982b), Pollard (1987), Murphy (1990), Tuljapurkar and Boe (1998) and Wong-Fupuy and Haberman (2004). See also Bengtsson and Keilman (2003) and Keilman (2005a).
The simplest method of forecasting mortality is to extrapolate life expectancy (a zero factor model), or some other life-table measure, and to use empiricallybased model life tables to obtain the age pattern; this has been facilitated by the expansion of life tables to include older ages (Coale, Demeny, \& Vaughan, 1983) and lower mortality (Coale \& Guo, 1989). The independent extrapolation of age-specific rates commonly involves mortality reduction factors or some fraction of the reduction factor (Goss, Wade, Bell, \& Dussault, 1998; Pollard, 1987).

Parameterisation (one-factor) functions of mortality have a long history (Forfar, McCutcheon, \& Wilkie, 1988; Gavrilov \& Gavrilova, 1991; Keyfitz, 1982b; Tabeau, Willekens, \& van Poppel, 2002). Among the best-fitting are the three-term functions capturing the age pattern of mortality in childhood, young adulthood (the accident hump) and senescence. Mode and Busby (1982) proposed an eight-parameter version, in which the three terms are estimated independently. The Heligman-Pollard model (Heligman \& Pollard, 1980) also has eight parameters; each term takes positive values only at relevant ages, the whole function being estimated in one step. The parameters have meaningful interpretations; however, high correlations between parameters, particularly for male mortality (see Hartmann, 1987), compromise this interpretability. Though the model fits well (Hartmann, 1987; Kostaki, 1988; Mode \& Busby, 1982; Rogers \& Gard, 1991), only Forfar and Smith (1987) found it useful for forecasting. Others encountered difficulties, particularly in determining the best base period for projecting the parameters (Keyfitz, 1991; Pollard, 1987). McNown and Rogers (1989) modelled the eight parameters as univariate ARIMA processes.

The Heligman-Pollard model represents senescent mortality using the Gompertz function; three variants were also proposed. Congdon (1993) demonstrated over-parameterisation in one nine-parameter variant; a reduced model also exhibited instability. Modifications at other ages have been made. Brooks, Sams, and Williams (1980) and Chauhan (1997) simplified the childhood term. Kostaki (1992) introduced a ninth parameter to improve the fit at young adult ages. Carrière (1992) proposed a three-term model with eight interpretable parameters which gave a better fit to US data than the Heligman-Pollard model; a four- 
term version with eleven parameters gave significant improvements. Carrière's use of a mixture of survival functions is equivalent to a multiple-decrement life table; the generalised framework can accommodate extra terms and other functions. The flexibility of this model has potential advantages in forecasting.

Rogers and Planck (1983) modelled mortality with the four-term nine-parameter version of the multiexponential function, comprising a constant, exponentially declining child mortality, a double exponential accident hump (the Coale and McNeil (1972) function) and Gompertzian senescent mortality. Rogers and Little (1994) found slightly poorer fits than the Heligman-Pollard model. In forecasting, McNown, Rogers and Little (1995) found interdependencies among parameters; five were fixed, and four were modelled by three univariate ARIMA processes and a bivariate autoregression. McNown and Rogers (1992) forecast total mortality and five cause-specific mortalities by fixing six parameters and modelling only the level parameters by univariate ARIMA models.

Siler (1983) proposed a five-parameter model that was found to fit better than either the HeligmanPollard or Mode-Busby models (Gage \& Mode, 1993); only the ten-parameter Mode-Jacobson (1984) model provided a better fit. Hannerz (1999, 2001a) also proposed a five-parameter model that fitted recent Swedish female mortality better than models which include a term for the accident hump. For males, however, the persistence of the accident hump necessitated an additional three-parameter term (Hannerz, 2001b). It appears that these have not been used in forecasting.

The relational model of mortality (Brass, 1971) linearly relates the logit transformations of observed and standard mortality. Forecasts based on this model include those by Golulapati, De Ravin, and Trickett (1984) for Australian male cohorts (see also Pollard, 1987), and Keyfitz (1991) for Canadian data. Zaba (1979) and Ewbank, Gómez de León, and Stoto (1983) developed four-parameter models to increase flexibility. Congdon (1993) adopted the Zaba model and forecast the relatively stable parameters by univariate ARIMA models. Hannerz (2001c) combined the features of relational models with parameterisation functions and model life tables in a regression model.
The most well-known method of mortality forecasting is the Lee-Carter method (Lee \& Carter, 1992) for long-term forecasting; see also Gómez de León (1990). The underlying two-factor model describes a one-parameter system with fixed age effects and has a homoscedastic additive Gaussian error structure. A unique least squares solution is found by singular value decomposition (SVD). Lee and Carter incorporated an adjustment of the level parameter so that fitted deaths match observed total deaths in any year; this avoids discrepancies arising from modelling on the logarithmic scale (Lee, 1992). The adjusted level parameter is modelled by time series methods; in almost all applications, a random walk with drift has been found to be applicable. Girosi and King (2006:40-49) review the method in detail.

Wilmoth (1993) developed a weighted SVD solution to the Lee-Carter model, providing a good fit without the need to adjust the level parameter, and a maximum likelihood solution; these methods gave almost identical results to the unweighted SVD in the case of Japan (Wilmoth, 1996). Carter and Lee (1992) addressed divergence by sex by estimating a joint level parameter while retaining sex-specific age effects. Lee and Nault (1993) jointly forecast provincial mortality. Lee (2000a) discusses these and other extensions of the method; data reconstruction for years where only total deaths are available is also possible (Lee \& Rofman, 1994). Tuljapurkar, Li, and Boe (2000) applied the method (without adjustment of the level parameter) to the $\mathrm{G} 7$ countries, finding a common pattern of linear decline in the level parameter. Lundstrom and Qvist (2004) used the method to examine changing trends in the Swedish mortality decline during the twentieth century.

The stability of the Lee-Carter method to structural change and initial conditions was examined by Carter (1996, 2000) and Carter and Prskawetz (2001). Tuljapurkar (2005) further demonstrates the robustness of the method. Li and Chan (2005) propose an outlier-adjusted method. Lee and Miller (2001) noted the influence of the adjustment procedure on forecast bias. Three modifications were introduced: the fitting period was restricted to post-1950 to reduce structural shifts, adjustment of the level parameter was by matching life expectancy, and observed rates were used as jump-off rates. Booth, Maindonald, and Smith (2002) also modified the method after finding 
historical departures from linearity in the Australian mortality decline: they proposed a method for determining the optimum fitting period for use in shorter-term forecasting when the relatively recent trend is linear, and adjusted the level parameter by fitting to the age distribution of deaths (a conditional maximum likelihood procedure). In a twenty-population comparison of the original method and these two variants, Booth, Tickle, and Smith (2005) found the Lee-Miller and Booth-Maindonald-Smith variants to perform roughly equally well overall over a 15 -year forecast period, but their ranking varied by sex; in other words, performance depends on situation. The Lee-Miller variant has been widely adopted as the standard Lee-Carter method.

Recent developments extend the applicability of the Lee-Carter method. Li, Lee, and Tuljapurkar (2004) demonstrate how, by assuming a linear trend in the level parameter, the method can be applied to populations with limited data at unequal time intervals. Li and Lee (2005) develop an augmented common factor method for overcoming the divergence problem, using a common factor to model group mortality and an additive population-specific factor. Such approaches make use of demographic convergence of mean levels; Edwards and Tuljapurkar (2005) note that substantial differences in variances should also be taken into account.

The Lee-Carter method has close similarities to the principal components approach used by Bell and Monsell (1991), and Bell (1997) discusses the similarities and differences in detail, demonstrating the importance of bias adjustment and the superiority in short-term forecasts of Lee-Carter over both Heligman-Pollard and principal components using all components. Whereas the Lee-Carter method uses only the first component, the principal components approach typically uses several, thereby allowing for greater flexibility in forecasting change. Higher order terms in the Lee-Carter method were modelled by Booth, Maindonald, and Smith $(2001,2002)$ and modelled and forecast using univariate ARIMA processes by Renshaw and Haberman (2003a). Hyndman and Ullah (2004) extend the principal components approach by adopting a functional data paradigm combined with nonparametric smoothing (penalised regression splines) and robust statistics, and fit univariate time series models to each compo- nent coefficient (or level parameter); the Lee-Carter method is shown to be a special case of this generalized approach.

Wolf (2004) proposed a Lee-Carter variant based on a first difference specification that integrates estimation of the Lee-Carter and time series models. De Jong and Tickle (2006) generalise and extend the Lee-Carter method by introducing a state space framework that also integrates model estimation and forecasting; they use B-splines to build in the expected smooth behaviour of mortality over age, and outline further possible extensions.

Integrated estimation and forecasting is a feature of modelling within the GLM framework. Renshaw, Haberman, and Hatzoupoulos (1996) proposed a two-factor model with two multiplicative terms: a Gompertz-Makeham graduation term and an agespecific trend adjustment term (see also Renshaw, 1991). This model was used to forecast UK mortality at ages $65+$ with qualified success: the optimum fitted model parameters did not necessarily generate plausible forecasts, for which lower-order polynomials are often required (Sithole, Haberman, \& Verrall, 2000). This study included a comparison with the standard actuarial practice of fitting the Gompertz-Makeham class of functions (see Forfar et al., 1988). Currie, Durban, and Eilers (2004) employed bivariate penalized B-splines to smooth over both age and time within a penalized GLM framework with extrapolation of the fitted surface over time; comparison with Lee-Carter revealed a much slower mortality decline.

In modelling mortality reduction factors using GLM, Renshaw and Haberman (2000) identified the conditions under which the underlying structures of the GLM and Lee-Carter models are identical; they later demonstrated the use of the Lee-Carter methodology for forecasting the reduction factors (Renshaw \& Haberman, 2003b). Renshaw and Haberman (2003c) developed a GLM-based approach that parallels the Lee-Carter method, including matching observed and expected total deaths. The important difference between the two approaches is in the treatment of time: in the Lee-Carter method time is a factor estimated by SVD, while under the GLM approach time is a known covariate. The GLM approach is based on a heteroscedastic Poisson (non-additive) error structure. Brouhns, Denuit, and Vermunt (2002) proposed a similar bilinear approach in which the Lee-Carter 
model forms the systematic component (predictor) in the Poisson error setting (cf Wilmoth, 1993). Renshaw and Haberman (2003a) compare the Lee-Carter, linear, and bilinear approaches with and without age-specific enhancement: in the Lee-Carter case such enhancement is achieved by including the second term, in the GLM case it involves a break point or hinge to allow for greater emphasis on recent trends, and in the bilinear case the two-term Lee-Carter model is implemented as a double bilinear predictor.

Forecasts based on cohort models are relatively few because of heavy data demands; where data are available the model may depend on the (inappropriate) experience of cohorts born in the nineteenth century if the entire age range is considered (e.g., Tabeau et al., 2001). This problem is reduced when only adult mortality is of interest. The cohort approach is free of tempo distortions (caused by changes in timing). Bongaarts and Feeney (2002, 2003 , 2005) propose an adjustment for tempo distortions in period life expectancy, with implications for forecasting. Other aggregate measures of mortality (Bongaarts \& Feeney, 2003; Guillot, 2003; Sanderson $\&$ Scherbov, 2005) may be considered.

In developing countries, restricted time series of observations limit the application of most forecasting methods. Lutz, Sanderson, Scherbov, and Goujon (1996) overcome this problem by deriving target life expectancy as the average expectation of experts. Girosi and King (2006) address the problem in the context of cause-of-death forecasting by incorporating prior information as covariates in a linear age-period regression model. The covariates, which may differ by age, may be lagged observed exogenous variables or forecasts of reliable longer time series; the model may thus be regarded as structural. Smoothness over both age and time can be incorporated as priors, based on empirical evidence or informed judgment. The method improves on existing Bayesian approaches by borrowing strength (or partial pooling) based on expected values rather than on coefficients, and maximises the use of prior information, hence maximising automation.

Regression models are easily extended to three factors, but (as noted above) age-period-cohort (APC) models must accommodate the identification problem (see also Van Hoorn \& De Beer, 2001). To address this, Wilmoth (1990) developed a modified model involving additive age and period effects and several multiplicative interaction terms; see also Wilmoth (2001). Tabeau (2001) concluded that mortality forecasting based on APC models is not feasible because of the difficulty in assuming future period effects (although age and cohort effects can be assumed to be fixed); only in forecasts of specific diseases would sufficient epidemiological knowledge be available. Caselli $(1996,2002)$ used the APC model to forecast mortality from leading causes.

Forecasting by cause of death has been advocated from a theoretical perspective as a means of gaining accuracy (e.g., Crimmins, 1981), but experience has largely proved otherwise. Little is gained from decomposition because of similar age patterns in the main causes; cause-of-death reporting is unreliable at older ages where most deaths occur; and causereduction may have minimal effect on total mortality (Murphy, 1995). Further, model misspecification and the presence of leading indicators (where changes in one cause systematically precede changes in another) can result in reduced accuracy from decomposition (Alho, 1991). The short time series of cause-of-death data also limits extrapolation. Using the multiexponential model, McNown and Rogers (1992) found no consistent discernible gain in accuracy from cause-of-death decomposition. Wilmoth (1995a) demonstrated that, for proportional rates of change models, mortality forecasts based on the sum of cause-specific forecasts will always be higher than those based on aggregate data because causes of death that are slow to decline come to dominate as other causes are more rapidly diminished. Using APC models for ages 60+, Caselli (1996) found this to be true for females but reversed for males. Tabeau et al. (2001) also found this difference between the sexes for France, Italy and the Netherlands, but not for Norway. Stoto and Durch (1993), Tuljapurkar (1998) and Wilmoth (2005) further discuss these issues.

Mortality forecasting based on (partial) causeelimination and cause-delay models make use of targeting and informed judgment (Manton, Patrick, \& Stallard, 1980; Olshansky, 1987, 1988); Kunst, Mackenbach, Lautenbach, Oei, and Bijlsma (2002) incorporated competing causes of death. These methods have often led to conservative forecasts of mortality reduction. Le Bras (2005) elaborates a cause-delay model of mortality change. 
Gutterman and Vanderhoof (1998) argue the case for structural models of cause-specific mortality change that take medical and other factors into account, despite the difficulties involved. Structural models of mortality at older ages relate lifestyle and other risk factors to functional status and mortality using vector autoregression, achieving some improvement over traditional time series and informed judgment methods (Manton, Stallard, \& Tolley, 1991; Manton, Stallard, \& Singer, 1992). However, their forecasting potential is limited by the short time series of risk factors, the large number of parameters and the non-linear interactions generating the mortality forecast. Epidemiological, structural and multistate approaches to cause-of-death forecasting are reviewed by Van Den Berg Jeths, Hoogenveen, De Hollander, and Tabeau (2001); (see also Van Genugten, Hoogenveen, \& De Hollander, 2001).

The forecasting of AIDS mortality is particularly difficult due to data limitations and inaccuracies, but methods have evolved rapidly. An early method involves the extrapolation of AIDS cases, while another uses a model of the progression from HIV infection to the onset of AIDS to back-calculate HIV infections, which are then forecast. The limitations of these methods are discussed by Bloom and Glied (1992) and Bos and Bulatao (1992). A third method incorporates a model of HIV transmission, and a fourth adds a behavioural model (Auvert, 1991; Bongaarts, 1989; Bos \& Bulatao, 1992; Bulatao, 1991). Oliveira and Mexia (2004) propose a method which uses data on infection and AIDS mortality without recourse to transmission and behavioural models.

For some purposes, forecasts of senescent mortality suffice. Using a two-factor regression-based approach, Heathcote and Higgins (2001a,b) modelled the log-odds of lexis-parallelogram mortality at ages $40+$ by an expression involving time, a quadratic in age and an age-time interaction with up to 24 additional predictors; in forecasting, naïve extrapolation gave implausible divergence by sex and subjectively-adjusted coefficients were used. The approach by Bongaarts (2005) adopts a shifting logistic model of the pattern of change over time in age-specific senescent mortality at ages $25+$. This one-factor parameterisation function makes use of the (nearly) constant slope parameter, or the equivalence of mortality decline and a shift of the senescent force of mortality schedule to older ages. In forecasting, the age pattern of change is fixed (constant proportionate decline) and the remaining two parameters are independently extrapolated: these are the levels of senescent and age-invariant background mortality. A shifting logistic is combined with the Lee-Carter method in long-term UN forecasts (Buettner \& Zlotnik, 2005; United Nations, 2004). A relatively constant age pattern of change at $25+$ was recently recommended for US mortality (Lee, 2000b).

A difficulty in senescent mortality forecasting is the adequacy of both the data and the models at the oldest ages, at which most deaths occur (Kannisto, 1994; Kannisto, Lauritsen, Thatcher, \& Vaupel, 1994; Tuljapurkar \& Boe, 1998). The Gompertz function has been widely employed (Olshansky \& Carnes, 1997; Pollard \& Valkovics, 1992). However, the Gompertz and other models were developed on truncated data and are not recommended for use much beyond the age of truncation: this is $85+$ in the Heligman-Pollard case (Heligman \& Pollard, 1980). At older ages, the Gompertz is inadequate (Boleslawski \& Tabeau, 2001). Willekens (2001) discusses the Gompertz function in the contexts of survival analysis and event-history analysis, with implications for modelling and forecasting. Models incorporating theoretical concepts of ageing are reviewed by Yashin (2001) and Yashin, Iachine, and Begun (2000).

Where data are truncated, extension to the oldest ages is necessary. Wilmoth (1995b) found the Coale and Kisker (1990) targeting method to fit well at the oldest ages, while Thatcher (1999) demonstrated good fits for the logistic model. Modelling by Renshaw and Haberman (2003c) supports the Coale and Guo (1989) method which also uses a target. A relational model was developed by Himes, Preston, and Condran (1994); no assumption is made about the upper limit. Buettner (2002) examined various methods including an adaptation of the Lee-Carter model. Boleslawski and Tabeau (2001) reviewed the efficacy of eleven functions in representing mortality at ages $80-110$, concluding that the Coale and Kisker (1990) method is superior when reliable data are available to at least age 90 (see also Alho \& Nyblom, 1997), but if data are reliable only for age 85 , the use of polynomials to extrapolating the age pattern is recommended. Buettner and Zlotnik (2005) found the Coale-Kisker 
method to be too restrictive in very long-term forecasts; they preferred the logistic model because it does not require specification of an upper limit.

\subsection{Fertility}

It is generally agreed that fertility and births are non-stationary series (Alho, 1992a; Ermisch, 1992). The difficulty in fertility forecasting stems from structural change, seen in the trajectory of total fertility (quantum), changing age patterns (tempo) and the complex association between the two. Forecasting success has been limited.

Zero-factor models are relatively common in fertility forecasting. Early forecasts focussed on events. McDonald $(1979,1981)$ used time series methods to forecast total births and first nuptial confinements, easily outperforming economic-demographic structural models in the very short term. Improvements were achieved by incorporating transfer functions linking total births to females of childbearing age and first nuptial confinements to marriages (thus, in effect, forecasting rates).

Forecasting fertility rates rather than births has several advantages including, in deriving births, making use of the fact that the number of women is known with near certainty for the first 15 years. Miller (1986) forecast total fertility and the mean age at childbearing by a transfer function model linking past quantum to current tempo. Age-specific fertility rates have been forecast by Congdon $(1980,1989)$ using regressions and ARIMA models incorporating periodic time and relative cohort size (in line with the Easterlin hypothesis), and by McDonald (1983) using simple time series models, with greater success than structural models.

Ortega and Poncela (2005) address the difficulty arising from structural change by jointly modelling total fertility trends for a (subjectively-defined) homogeneous group of countries. They use dynamic factor models to estimate one or two common factors capturing the non-stationary average total fertility trajectory and a stationary deviation from the average; they forecast these factors using time series methods. Compared with univariate models and a vector autoregression, the approach yielded substantial gains in forecast accuracy, particularly over longer horizons.
The approach of Lutz, Sanderson, Scherbov, and Goujon (1996) implicitly deals with the problem of past and potential future structural change by deriving target total fertility as the average expectation of a group of experts. This approach has also been used with disaggregation by education by Lutz and Scherbov (2004).

Various theories underpin the structural modelling of fertility; brief reviews are found in Keyfitz (1982a) and Ermisch (1992). Ahlburg (1982) achieved greater short-term accuracy for total births than US official forecasts; his model included marriage, divorce and female labour force participation. Ahlburg also forecast US births using a simple Easterlin relative cohort size model, identifying cycles of alternate generations (Ahlburg, 1983), and forecast Canadian births using a similar model based on births both one and two generations ago (Ahlburg, 1986).

Structural modelling of age-specific fertility rates generally involves separate modelling by age but estimation as 'seemingly unrelated regressions.' Ermisch (1983) modelled three age groups in this way as functions of women's and men's earnings, relative cohort size and female lifetime employment rates, and forecast them. Poorer results for women aged 30-34 than 20-24 were attributed to heterogeneity in fertility responses to economic change by parity with, the changing parity distribution of women producing unstable responses (Ermisch, 1992). Frameworks that build in the sequential nature of childbearing are thus preferred (De Cooman, Ermisch, \& Joshi, 1987; Ermisch, 1988). Ermisch (1992) adopted such a model of fertility rates by birth order; short-term forecasts based on this model were not sensitive to assumptions about the explanatory variables, but neither were they a substantial improvement on time series models, and in the longer term, the main advantage was not in forecasting but in exploring different scenarios for policy purposes (Ermisch, 1992:220).

Several parameterisations have been applied in the modelling of age-specific fertility rates, including the beta, gamma and Hadwiger functions. Hoem et al. (1981) compared several functions, finding the gamma density and the Coale-Trussell (Coale \& Trussell, 1974) function to be equally superior except for highly parameterised splines; they noted the Coale-Trussell advantage of parameter interpretability for forecasting. Rogers (1986) considered the Coale- 
Trussell model to be overly complex and suggested the direct use of the double exponential function; in other words, the third term of the multi-exponential function (Rogers \& Little, 1994). The double exponential was found to fit better to fertility patterns that were relatively symmetrical, and less well to the flatter curves of the 1980s (Knudsen, McNown, \& Rogers, 1993), whereas the Coale-Trussell model was superior in cases of higher fertility in the 1960s (Rogers, 1986:51). The four parameters of the double exponential are not readily interpretable; in the absence of time series data, Rogers (1986) regressed each on the gross reproduction rate (GRR) and assumed future GRR in forecasting. Knudsen et al. (1993) partially reparameterised the model, the new parameters being the mode and modal value, and related total fertility to the remaining two parameters (via the gamma density), considerably improving forecastability; univariate ARIMA models performed well in out-ofsample forecasts of US fertility, despite strong interactions among parameters.

The more tractable relationship between the three pattern parameters of the gamma density and the mean and variance of childbearing was made use of by Thompson, Bell, Long, and Miller (1989) for shortterm forecasting of age-specific fertility; they directly forecast the level, mean and standard deviation of childbearing using a vector autoregression. The gamma density was also used by Keilman and Pham (2000) in long-term interval forecasts of Norwegian fertility involving a vector autoregression of three of the four parameters (governing level and age pattern, the parameter representing the minimum age of childbearing being constant).

Congdon (1990) used the Hadwiger function, forecasting the four parameters using univariate ARIMA models; with hindsight, this compared favourably with a structural time series model incorporating cyclical and trend factors, relative cohort size and female job opportunities. Congdon (1993) made a similar comparison using the reducedform Hadwiger function for both period and cohort fertility. He noted that all four-parameter functions are over-parameterised; of the reduced-forms, the beta gave a better fit but the Hadwiger has the advantage of parameter interpretability. Chandola, Coleman, and Hiorns $(1999,2000)$ used the reduced Hadwiger function to model European fertility: while it provided a good fit for several countries, for others it was unable to capture the slight hump at young ages that has recently developed. For these countries, a mixture model was used to combine Hadwiger functions for non-marital and marital fertility, making use of disaggregation. The general approach has potential for forecasting.

Brass $(1974,1981)$ developed the relational Gompertz model which linearly relates observed fertility to a suitable standard. The model is used with incomplete cohort data, or to produce series of the level and two pattern parameters for forecasting. Parameter interpretation was improved by Zeng, Zhenglian, Zhongdong, and Chunjun (2000) in relating the pattern parameters to the median age and interquartile range. Murphy (1982) investigated the use of relational Gompertz models in forecasting. In general, structural change limits the use of parameterisation functions and relational models for forecasting, especially where (as is desirable) vector autoregressions are employed.

The Coale and McNeil (1972) double exponential has been widely shown to fit first births well (Bloom \& Trussell, 1984). Bloom (1982) used this model to forecast first births for incomplete cohorts, with limited success for younger cohorts. Trussell and Bloom (1983) allowed the parameters to depend on covariates; Bloom and Trussell (1984) then forecast childlessness for incomplete cohorts. The CoaleMcNeil function was elaborated by Kaneko (2003) as the generalized log gamma distribution and used to forecast first marriage and parity-specific fertility for incomplete cohorts.

Evans (1986) used linear regression to predict first birth fertility after age 25 from the proportion attaining parenthood by age 25 (quantum) and the ratio of fertility at 15-19 and 20-24 (tempo); overall fertility was similarly forecast. Martinelle (1993) forecast first birth rates and childlessness using a regression model of incomplete cohort fertility that took education into account. Chen and Morgan (1991) and Morgan and Chen (1992) showed that the Bloom approach was sensitive to censoring below age 30, while the Evans approach was in fact based on period effects, and concluded that it was preferable to base forecasts on the period life table model which assumes that current rates will persist into the future. 
Ryder (1990) also advocated a period approach, incorporating continued patterns of change. The dominant effect on fertility change in the short- to medium-term is period rather than cohort; the relationship between the two and their relative advantages in forecasting have been extensively discussed (e.g., Ní Bhrolcháin, 1992; Ryder, 1983). Bongaarts and Feeney $(1998,2005)$ proposed an adjustment of period total fertility to take tempo effects into account when data by parity are available. Kohler and Philipov (2001) extended this adjustment to include variance effects. While unadjusted fertility remains the basis of population forecasting, adjusted measures aid understanding and inform future trends. Any potential gains in forecast accuracy are important because long-term population forecasts depend heavily on long-term total fertility forecasts.

Kohler and Ortega (2002) proposed a tempoadjusted period parity progression measure that can be used to forecast the fertility of incomplete cohorts conditional on a level of fertility and a postponement pattern derived from past period trends. Sobotka (2005) used this method to derive tempo-adjusted first birth probabilities, which he used as the low assumption contrasted with the high assumption based on unadjusted probabilities, separating tempo and quantum effects.

Lee (2005) charts his 30-year journey in fertility forecasting, describing how the very idea of modelling (post-transition) fertility as a random process was widely rejected by demographers for the first 20 years! Forecasters were more receptive: in an elaboration of earlier ideas, Lee $(1992,1993)$ modelled agespecific fertility rates over time using a single timevarying fertility index (the method parallels the LeeCarter method for forecasting mortality). To address the problems arising from structural change, lower and upper bounds and an ultimate (average) level were imposed (Lee, 1993; see also Lee, 1999). Lee and Tuljapurkar (1994) used this model with a different ultimate level and no bounds. Tuljapurkar and Boe (1999) further evaluated the performance of the approach. Carter and Lee (1986) used the approach in a joint model of nuptiality (age and period) and marital fertility (duration and period).

The Lee method is a principal components method. Principal components methods were used by Bozik and Bell (1987) to forecast age-specific fertility, using the first four components and the level in a vector autoregression. A principal components approach was also used by Sivamurthy (1987). Hyndman and Ullah (2004) also adopted this general approach for forecasting Australian fertility using functional data methods; the logarithms of fertility rates were, after smoothing, modelled by three basis functions, and the coefficients of these orthogonal functions were forecast using univariate time series models. Bell (1992) discusses the use of principal components and various other models in time series forecasting of agespecific rates; see also Bell (1997).

Cohort forecasting of fertility makes lesser demands on data than mortality, but may be compromised by structural change. $\mathrm{Li}$ and $\mathrm{Wu}$ (2003) modelled fertility for completed cohorts by age and cohort using the Lee (1993) model, and combined the estimated fixed age effect and incomplete cohort observations to forecast the cohort effect, thereby completing that cohort's fertility. The method is restricted to completing cohort fertility when certain assumptions are met.

De Beer (1985) developed the CARIMA (cohortARIMA) model for short-term forecasting which was successful in identifying turning points 6 or 7 years ahead in first and second order births. The model forecasts age- or duration-specific fertility rates for cohorts using time series methods, taking into account error covariances and additive period effects, both of which are modelled as ARIMA processes. The unobserved fertility of incomplete cohorts is forecast on the basis of observations at younger ages and for older cohorts. As with ARIMA models in general, a disadvantage of the CARIMA model is the difficulty in interpreting its parameters.

Using post-1950 data for four European countries, De Beer (1989) compared four models: the CARIMA model, a multiplicative APC-ARIMA model (Willekens \& Baydar, 1986), cubic spline models of age-specific fertility rates and an ARIMA forecast of total fertility. An advantage of the APC-ARIMA model was its greater parameter interpretability, but its usefulness is strictly limited to short-term forecasts. The short-term CARIMA and APC-ARIMA forecasts performed slightly better than the ARIMA forecast of total fertility, while the CARIMA forecasts were more accurate than those from the APCARIMA model when parity-specific rates were used 
(except anomalously for second births). The relative accuracy of the spline and CARIMA models was highly dependent on the position of turning points in the fitting period: either model could produce large forecast errors.

Birth expectations might be regarded as a potentially useful exogenous variable in cohort fertility forecasting, particularly in forewarning of changing trends (Willekens, 1990), but this is often not the case: not only are the expectations data relatively unstable over time, but they also tend to lag rather than lead actual fertility (Ahlburg, 1982; Bongaarts \& Bulatao, 2000:93; Lee, 1980; Ryder, 1990; Westoff, 1981). Poor correspondence between stated expectations and later births has been found using record linkage (Noack \& Østby, 1985) and longitudinal surveys (Calhoun \& De Beer, 1991; Quesnel-Vallée \& Morgan, 2003). Though correspondence is greater at the aggregate level because of compensating discrepancies, expectations data are generally regarded as unreliable (Morgan, 2001; Van Hoorn \& Keilman, 1997). Nonresponse contributes to the problem (Morgan, 1981, 1982; Van de Giessen, 1992; Van Hoorn \& Keilman, 1997). Further, Lee (1980) demonstrated that minor fluctuations in desired completed family size will generate major fluctuations in period fertility, which determines annual births and consequent age structures (with effects on births a generation later).

Birth expectations data are often used qualitatively; this was the case for many years in US official forecasts (Long, 1981, 1984). Short-term forecasts of total US births were found to be less accurate than those derived by structural modelling (Ahlburg, 1982). Based on extensive US evidence, Hendershot and Placek (1981:312) concluded that whether birth expectations data were useful or not depended on the period considered and on informed judgment.

Given the discrepancies between expectations and realisations, the direct use of expectations data is illadvised. Models (e.g., De Beer, 1991; Lee, 1980, 1981) are used to 'correct' the data for forecasting, but none is considered ideal and their use is limited (Van Hoorn \& Keilman, 1997). Calhoun and De Beer (1991) developed a bivariate econometric model of children ever born and additional expected births allowing for the structural relationship between the two. Morgan and Chen (1992) dismissed birth expectations data as a basis for first birth forecasting.

\subsection{Migration}

International migration has been largely neglected in demographic modelling and forecasting. Wilson and Rees (2005) note the difficulties involved. A review of the practice in 30 industrialised countries (George \& Perreault, 1992) found that most used simple assumptions (at best considered a naïve forecast) of net migration of zero or continuing at the current level with a fixed age pattern. Howe and Jackson (2005) found that little had changed, though there were some exceptions: the UK and Japan now use extrapolation with informed judgment, while the Netherlands combines time series and informed judgment in deriving assumptions for 12 migrant groups. Theories of international migration have not often been quantified in forecasting (Howe and Jackson, 2005); informed judgment has played a central role.

Increasing sophistication in the use of informed judgment reflects the growing importance of migration in determining population change. De Beer and Van Wissen (1999) grouped European countries according to five demographic patterns, and adopted two assumed net migration rate targets in 2050 characterised by 'uniformity' under a strong economy and 'diversity' under a flagging economy. Bijak, Kupiszewski, and Kicinger (2004) also grouped European countries and used target net migration rates for intra- and extra-European migration with exponential interpolation of migrant numbers. A detailed study of European migration and its correlates recommended that immigration and emigration are best forecast separately using one generic framework, taking into account reasons for immigration and qualitative and quantitative information in countryspecific approaches (Hilderink et al., 2002). The use of qualitative and quantitative information can be formalised by the expert-based approach of Lutz and colleagues (Lutz, 1996).

The reason for migration is taken into account by decomposition; levels and age-sex patterns are forecast for the different types of migrants, such as labour, dependents and asylum seekers (note that these are not population characteristics). Disaggregation of immigrants by citizenship is also important (Hilderink et al., 2002). Decomposition and disaggregation are increasingly employed as data become more readily available. This approach permits in- 
formed judgment to focus on the circumstances of specific groups. In general, however, the unpredictable nature of economic and political developments, including migration policies, present considerable uncertainties for forecasting.

De Beer (1997) used time series methods to model aggregate immigration and emigration, both as firstorder autoregressive processes. Additionally, net migration was modelled by a first-order moving average. The three models gave consistent results, but informed judgment considered the net forecast (which was only two-thirds of the average observed over the last decade) to be too low. Informed judgment was incorporated as the target in a fiveparameter "extrapolation-target" model; three parameters govern the extent to which the forecast depends on past observations, the fourth is the target and the fifth is the speed at which the forecast approaches the target. The parameters are all interpretable and in principle can be derived from fitting the model to observations. Keilman and Pham (2004) also forecast immigration and emigration by time series methods; the ARIMA models were $(1,0,1)$ for immigration and $(0,1,0)$ for emigration. The forecast series were randomly broken down by sex; the age patterns were based on six-parameter multi-exponential models (see below).

Miller (2002) used time series methods in forecasting total net migration to California: for domestic migration, the net rate was modelled by an $\operatorname{AR}(1)$, and for international migration, the proportion of legal migrants intending to reside in California was also an $\mathrm{AR}(1)$; adjustments were made for illegal migration and the age distributions were assumed to be fixed. Miller and Lee (2004) used a similar approach. Wilson and Bell (2004) also applied time series methods in forecasting numbers of immigrants and emigrants for Australia.

The multi-exponential function originated in modelling the age pattern of migration (Rogers \& Castro, 1981; Rogers, Raquillet, \& Castro, 1978; Rogers \& Watkins, 1987). The four-term model comprises a constant, exponential child migration, double-exponential labour migration, and retirement migration (zero, exponential or double exponential), giving 7-11 parameters in total. With the addition of a postretirement term (Rogers, 1988), the full model has 13 parameters (Rogers \& Little, 1994). Congdon (1993) suggested a three-parameter bell-shaped curve for retirement migration. The model does not easily lend itself to forecasting (Congdon, 1993; Rogers, Castro, \& Lea, 2005), but see also George (1994): fitting requires non-linear regression methods with good guesses for the initial values of parameters which are highly correlated and potentially highly variable over time. Rogers et al. (2005) present three alternative linear estimation procedures for "simplified" and "complete" models which produce greater temporal stability and some improvements in interpretability; these may present possibilities for forecasting.

Zaba $(1985,1987)$ extended relational modelling to migration by developing three-parameter models of immigration and emigration based on a simple linearizing transformation. Congdon (1993) applied this method to out-migration data; the fit was further improved by adding quadratic and cubic terms in the standard. Though some fluctuation occurred in the parameters, trends were apparent, and the potential for forecasting was noted.

\section{Probabilistic population forecasting}

Many of the forecasting methods discussed above have been used to obtain only deterministic point forecasts, particularly in the earlier period. More recently, the variability of forecasts has become of central concern (Lee, 1999; Lee \& Tuljapurkar, 2000). The importance of taking component uncertainty into account through probabilistic population forecasting has increasingly been recognised. Exactly how to do this has been the subject of much recent debate, not least because estimating the uncertainty is itself uncertain (Keilman, 2001a; Lutz, Sanderson, \& Scherbov, 1999). Several approaches have been proposed, the methodological details of which are still evolving. Previous reviews of this work include De Beer (2000), Lee $(1999,2000 b)$ and Keilman (2005b); see also Lutz \& Goldstein (2004a).

\subsection{Stochastic population renewal}

From a statistical viewpoint, the ideal approach to population forecasting is the fully probabilistic approach; its advantages overcome the limitations of traditional deterministic projections (Section 2). 
Importantly, probabilistically consistent prediction intervals are produced: uncertainty is expressed as a probabilistic prediction interval for any desired function of the forecast age distribution, and any probability can be chosen. The use of probability in the definition of intervals provides a means of ensuring consistency among component intervals, and separates specification of the population prediction interval from component intervals. Further, the use of probability increases the utility of population forecasts in risk assessment (Tuljapurkar, 1992); the forecast may be accessed as a database (Alho \& Spencer, 1991). A prediction interval is, however, conditional on the forecaster's particular choice of method and the assumptions or judgment used.

The fully probabilistic population forecast is generated through stochastic population renewal in one of two ways; both employ the cohort-component method. The analytical approach involves the specification of a stochastic Leslie matrix (with relevant covariances); this approach was pioneered by Sykes (1969) and further developed by others (Alho, 1990; Alho \& Spencer, 1985, 1991, 1997; Cohen, 1986; Lee \& Tuljapurkar, 1994). This approach permits the assessment of the relative contribution of errors in mortality, fertility and migration to population error (Alho, 1992a). Using stochastic renewal theory, Tuljapurkar (1992) showed that population renewal is not a closed recursion in the presence of autocorrelation and that the forecast population size (or part thereof) is (asymptotically) lognormal. A problem with the analytical approach is its complexity and the need for approximations and simplifying assumptions. The second approach avoids these problems by using Monte Carlo simulation in which each step of the forecast is generated by randomly drawn parameters for the distributions of mortality, fertility and migration. The population distribution is derived from the percentiles of the set of forecasts. This method is commonly used.

The cohort-component model does not itself give rise to forecast uncertainty as it is an accounting system. However, errors are propagated by the process of population renewal, producing complex combinations of errors in forecast population size and structure (Alho \& Spencer, 1985). These errors may cancel each other out depending on the degree to which they are correlated. Thus in (fully) probabilistic population forecasts, correlations among errors in component forecasts affect the degree of uncertainty of the population forecast.

\subsection{Correlations among forecast errors}

Four types of correlation among forecast errors may occur: temporal or serial (auto)correlation, correlation across age, correlation between demographic components, and correlation among populations by sex or within a coherent region.

First-order autocorrelation of errors is relatively high for annual demographic rates. However, it is the long-run mean (of fertility in particular) rather than annual values that determine population growth, and over the long term (a century or so), temporal correlation is weak (Lee, 1993). Such correlations must be taken into account.

Correlations in forecast errors across age are generally positive because forecasting methods often take advantage of the regularity of age patterns or assume a fixed age pattern. Further, the conditions resulting in high or low annual demographic rates often apply over the whole age range. Correlations across age in mortality contribute directly to larger errors in forecast populations. For fertility the effect is less important because it is the number of births that matters rather than the age of the mother. Alho (1998) found correlations of at least 0.89 between neighbouring ages for mortality and fertility rates. Lee and Tuljapurkar (2000) and others have concluded that perfect correlation can be assumed.

Correlations between demographic components (and the jump-off population) are only likely to be important for developing countries where development factors may underlie changes in all three components (e.g., Lutz, Sanderson, \& Scherbov, 1996). For industrialised countries such correlations are negligible (Alho, 1992a; Keilman, 1997; Lee \& Tuljapurkar, 1994). Correlations among populations within regions cannot be ignored: for example, correlations related to common patterns of change in mortality or fertility must be taken into account in sub-Saharan and European forecasts (Lee \& Tuljapurkar, 2000; Lutz, Sanderson, et al., 1996). Positive correlations between the sexes in mortality and migration also arise; the common assumption of perfect correlation results in some overestimation of 
population forecast uncertainty (Keilman, Pham, \& Hetland, 2002).

\subsection{Sources of error}

In forecasting demographic rates, Alho (1990) classified error into four different, but conceptually dependent, sources: model misspecification, errors in parameter estimation, random variation and errors in informed judgment (see also Keilman, 1990). Model misspecification may occur with respect to the assumed underlying model (e.g., a parameterisation function) or the time series model or both. Informed judgment in statistical modelling refers to 'prior' beliefs about model parameters and the weight given to them in forecasting; these weights can be estimated by mixed estimation (Alho, 1992b). In addition, the basic data are subject to random and non-random measurement error (Stoto, 1988); see also Lee (1999). Alho (2005) provides a useful discussion of the roles of probabilities and judgment. For population forecasts, an additional source is measurement error in the jump-off population, though this is usually negligible for industrialised countries.

\subsection{Model-based ex ante error estimation}

Stochastic population renewal makes considerable demands in terms of variance-covariance error structures. One way to estimate this uncertainty is to use ex ante estimates produced by extrapolative methods. However, estimating uncertainty in this way is highly uncertain because the estimate depends on the particular forecasting method used (Cohen, 1986; Lee, 1974; Sanderson, 1995). Standard methods may lead to implausibly wide intervals, and judgment is required in limiting the series or imposing constraints (Keilman, 2002; Keilman \& Pham, 2000; Lee, 1993; Tuljapurkar \& Boe, 1999). Time series methods do not take into account this and several other sources of uncertainty (Lee, 1999), nor were they developed for long-term forecasting, for which both point forecasts and prediction intervals may be unrealistic (Sanderson, 1995). They can, however, provide a standard against which other estimates are compared (De Beer, 1988).

An alternative is to model forecast errors per se (Alho \& Spencer, 1985, 1990a,b, 2005; Cohen, 1986).
Alho and Spencer (1985) constructed prediction intervals for short-term horizons from a parametric model of the main sources of error: model misspecification, parameter estimation and informed judgment. Estimates of uncertainty based on naïve forecasts provide a conservative baseline for the assessment of forecast errors. Alho (1998, 2003) related errors produced by historical naïve forecasts for Finland to forecast length, and used this to inform prediction intervals for new Finnish forecasts. Alho (1997) borrowed information on the variance and autocorrelation of errors from one country for forecasting fertility for another, and also modelled inter-country correlations. Alho and Spencer (1997) describe how to implement this approach in population forecasting using the analytical approach.

\subsection{Expert-based ex ante error estimation}

In many countries, data availability limits the estimation of variance-covariance structures for fully probabilistic population forecasting. The expert-based approach circumvents this problem. Component target forecasts (see Section 3.2) are supplemented by expert specifications of high and low values, which on average are assumed to correspond to $90 \%$ prediction intervals of a normal distribution (Lutz, Sanderson, et al., 1996; Lutz, Sanderson, \& Scherbov, 1997; Lutz \& Scherbov, 1998). The method is robust to changes in the probability and the distributional form (Lutz, Sanderson, \& Scherbov, 1999; Lutz \& Scherbov, 1998), but is not suited to short-term forecasting where variation may be greater than can be captured by the combined assumptions of linearity and normality (Lutz, Sanderson, et al., 1996); Alders and De Beer (cited in De Beer \& Alders, 1999:4) show that this problem is not negligible in the long term.

In population forecasts, the path of each component is a random line (or piecewise linear path) determined by a single random draw from the abovedefined normal distribution. Thus, for example, total fertility is positioned at the same percentile over the entire period, which may imply confined changes in trend but does not allow, for example, the meanderings of a random walk. These random lines are randomly combined into scenarios: each random scenario is the result of the three random numbers determining the trajectories of mortality, fertility and 
migration. The distributions of population size, structure and other output variables are obtained from the set of repeated scenarios.

The differences between this random scenario approach and the fully stochastic approach are discussed in detail by Tuljapurkar, Lee, and Li (2004); see also Tuljapurkar (1997). The criticism that the perfect autocorrelations in the random lines do not permit a truly random sample path (e.g., Lee, 1999) contributed to the relaxation of the assumption of perfect autocorrelation by the addition of a random term (Lutz, Sanderson, \& Scherbov, 1999, 2001). Further, in response to criticism that expert expectation is overconfident and produces overly narrow prediction intervals, which occurs particularly when the recent trend is unchanging (Keilman, 1990), the methodology was adapted to place greater emphasis on expert argument rather than opinion (Lutz, Goujon et al., 1999; Lutz, Sanderson, \& Scherbov, 2004). Doubt is also cast on the ability of experts to specify values representing probability bounds, and on whether they consider the bounds of annual point forecasts or temporal averages (Lee, 1999). Alho (2005) also raises the problem of 'expert flocking' resulting from the common information base and a desire to conform. As already noted, Lutz, Goldstein et al. (1996) argue that the expert-based approach is the only meaningful way to capture future uncertainty because structural change and unexpected events are likely to occur. Others argue that such occurrences are reflected in the error variances of time series models (Lee, 1999).

Alders and De Beer (2005) discuss the use of expert knowledge in the specification of uncertainty in forecasting Dutch mortality. As different estimation methods produced substantially different prediction intervals, judgment was used based on four considerations: smoking trends by sex, possibilities for mortality decline at young ages, ongoing rectangularisation of the survival curve, and the role of medical advances. These and other considerations are built into the deterministic forecasting model (Van Hoorn \& De Beer, 2001, cited in Alders \& De Beer, 2005:50). The approach is described as 'argumentbased forecasting' (Alders \& De Beer, 2005:57). Expert opinions have also been used in Finland to derive prediction intervals for migration (Alho, 1998, 2005).

\subsection{Ex post error estimation}

Errors in past forecasts can be used to estimate the variability in future forecasts, on the assumption that the future will not differ from the past and that errors can be modelled. Uncertainty over the forecast period is derived from the overall estimate of the variance according to the estimated (or assumed) degree of autocorrelation. A form of targeting may be used, where the variance is specified for the last year of the forecast and interpolation is used for earlier years, for example by specifying the $95 \%$ prediction interval and assuming that variance increases with time as in a random walk. Different patterns of evolution may be required for different components, and for cohort and period fertility (De Beer \& Alders, 1999). Extrapolative forecasts of ex post errors may be made (e.g., De Beer, 1997).

Prediction intervals based on ex post errors are attached to a separately-derived (deterministic) forecast, with which they should be consistent (Van Hoorn $\&$ De Beer, 2001). The method provides uncertainty estimates for fully probabilistic population forecasting (assuming perfect correlation across age and zero correlation between components). It is advantageous in situations where a judgemental point forecast is preferred, for example when recent structural change limits extrapolative methods. However, ex post errors for periods of structural change may not be relevant for future forecasts (De Beer \& Alders, 1999).

Ex post errors were first applied to official population forecasts (rather than component forecasts), where they are essentially a measure of the accuracy of the traditional cohort-component medium scenario. Keyfitz (1981) and Stoto (1983) used variability in ex post errors in the population growth rates of UN projections to derive probability distributions for population size. Issues about the correlation of errors do not arise, and uncertainty in the age-sex structure is not addressed, though the method could be applied independently to any measure. These and other studies of errors in UN population projections (Bongaarts \& Bulatao, 2000; Keilman, 1999, 2001b; Pflaumer, 1988) found evidence that errors in forecast growth rates were greater for high growth regions and earlier base (jump-off) years, and some evidence that accuracy improved over time; improved data accuracy and more stable demographic conditions contributed 
to these findings. Errors in the estimated base population were not insignificant. Further, forecast accuracy was generally found to decline with increasing forecast horizon and to be better for large populations and worse at young and old ages. Based on such findings and cross-country correlations, the study reported by Bongaarts and Bulatao (2000) developed a statistical model for the uncertainty in national and global population forecasts.

Detailed studies of national population forecasts for developed countries (De Beer, 1997; Keilman, 1990, 1997) examined errors in mortality, fertility and migration rates and events, and used multivariate methods (an APC model) to separate out the effects of the length of forecast horizon, the difficulty of the particular period and the base year. Other relevant considerations include the interaction between difficulty and forecast method; the role of luck and the reasoning behind the choice of method; the causes of forecast error (for example, model misspecification or an actual change in trend); and bias towards older forecasts because recent forecasts can only be analysed in the short term (De Beer, 2000). Keilman $(1990,1997)$ found no clear evidence of improvement over time in forecasting birth and death rates.

\subsection{Complementarity of approaches}

The three approaches to the estimation of forecast uncertainty were at first regarded as more or less mutually exclusive, but many applications have made use of and demonstrated their complementarity (e.g., Alders \& De Beer, 2004, 2005; Alho, 1997; De Beer \& Alders, 1999; Keilman et al., 2002; Lee, 1993; Lutz, Sanderson, \& Scherbov, 2001; Van Hoorn \& De Beer, 2001). Keilman and Pham (2000) derived prediction intervals for age-specific fertility in the short to medium term which take into account uncertainty arising from sampling variability, parameter estimation in both the gamma functional representation of the age pattern and the time series forecasting model, and residual variance in the time series model. Keilman and Pham (2004) used ARCH time series models (assuming the variability of the past 100 years) to derive prediction intervals for total fertility in Nordic countries and compared them with intervals based on ex post errors and the naïve (constant) forecast: the three estimates were similar, indicating that time series estimates are not excessively wide by this measure.

In comparing estimates from different approaches, it is important to bear in mind the distinction between time series intervals for annual point forecasts and intervals for temporal means. Assumptions about future demographic rates refer more to temporal means than to annual meanderings, so that ex post errors and expert-based errors are comparable with ex ante errors for temporal means (Lee, 1993; Lee \& Tuljapurkar, 2000).

\section{Direct population forecasting}

Rather than forecast population size by the cohortcomponent method, simple or direct methods maybe used. Ahlburg (1987b) used an autoregressive model. Leach (1981) re-examined the use of the logistic function, concluding that it provides an acceptable model of long-term change that can be more accurate than the cohort-component method; he attributed this to an ability to model the 'mechanism for selfcorrection' (p.102). Further, Leach argued that component forecasts (based on long-term trends) should be constrained to match population change forecasts by the logistic model. Similar views were expressed by Pflaumer (1992) who also advocated the use of time series methods to provide a baseline against which more complex methods could be gauged. McNown et al. (1995) applied this test to point and interval cohort-component forecasts based on components forecast using the multi-exponential model.

Many studies have examined the relative performance of simple and cohort-component models of population forecasting. Most have found constant growth models or standard time series models of population size or growth to be at least as accurate (e.g., Cohen, 1986; Long, 1995; Murphy, 1984; Pflaumer, 1992; Smith, 1997; Smith \& Sincich, 1992; Stoto, 1983). Keyfitz (1981) found complexity to be an advantage. Bongaarts and Bulatao (1999) found that most of the variation in World Bank traditional cohort-component population projections can be accounted for by simple models. Lee, Carter, and Tuljapurkar (1995) discuss the relative merits of cohort-component and direct forecasting, including the possibility of disaggregating by age and sex after 
forecasting the total. Rogers (1995c) reviewed the evidence over a broader range of models and provided a typology of model complexity: a main conclusion, already noted, is that much depends on the particular trends in the historical period that forms the basis of the forecast.

Smith (1987) compared three direct forecasting methods for population size, finding the base period to be influential and larger forecast errors for longer forecast horizons, high base period growth rates and smaller populations. The relationship between forecast accuracy and forecast horizon was approximately linear, but no consistent relationship was found for bias (Smith \& Sincich, 1991). The length of the base period has also been found to have an (inverse) effect on forecast errors (Smith \& Sincich, 1990). A nonlinear inverse relationship between population size and forecast accuracy was also found among small populations (Tayman, Schafer, \& Carter, 1998).

For very long-term deterministic forecasting, ergodicity allows the initial age-sex structure to be ignored, except for its effect on population momentum (see Tuljapurkar and Lee (1997) for the stochastic case). Goldstein and Stecklov (2002) proposed an analytical model that adopts a formula for population momentum under changing fertility (Li \& Tuljapurkar, 1999, 2000) with extensions to allow for nonreplacement ultimate total fertility and changing mortality. The method requires only aggregate measures: birth and growth rates and life expectancy.

\section{Progress and progression}

It has been seen that a considerable volume of research has been undertaken in demographic forecasting over the last twenty-five years. New models and methods have been developed and probabilistic forecasting has been introduced. Much of this research is recent: methods are still in development and many have yet to be fully evaluated. Further developments can be expected in the coming years.

\subsection{Overview of methodological developments}

Several broad conclusions about methodological developments in demographic forecasting can be drawn from this review. First, zero-factor models of aggregate measures are inadequate, not least because the assumption of a fixed age distribution is unrealistic. The independent forecasting of age-specific rates may produce irregular and implausible age patterns. Second, one-factor models have not generally been successful in forecasting because of parameter uninterpretability and over-parameterisation; forecasts based on these methods may produce implausible trends and age patterns, especially where parameter time series models are univariate. The shifting logistic model of senescent mortality (Bongaarts, 2005) has the advantage of independent parameters; this method has yet to be evaluated.

Third, two-factor GLM methods, where time is a covariate, often produce implausible forecast trends. Fourth, the Lee-Carter method involving a single time-varying parameter appears to produce plausible trends and permits a changing age pattern, though the fixed pattern of change may produce implausible age patterns in the longer term (Girosi \& King, 2006:45). Fifth, individual expectations are not a good basis for demographic forecasting; the validity of expert expectations is also open to question and has yet to be fully evaluated. Last, structural models have not proved useful for forecasting except perhaps for epidemiological models used in short-term forecasting of mortality from certain causes.

It would appear then that little progress has been made along the developmental path of forecasting referred to by Willekens (1990). Many of the models and methods developed in recent times focus on the extrapolation of stable patterns and the associated estimation of uncertainty in the transitionary first stages. Others focus on the use of expert opinion, qualitatively but not quantitatively taking demographic knowledge into account. Forecasting with explanatory structural models has not been significantly advanced. Neither have decomposition and disaggregation been used to advantage. While multistate forecasting has been employed for spatial disaggregation, it has not been widely adopted for other dimensions. Microsimulation is limited (computationally) to manageable sample populations so as to accommodate more detailed disaggregation. Further, many microsimulation models are based on constant transition probabilities (or rates), so that the forecast is determined only by the initial distribution of the sample population. 
However, other progress has been made: forecasting knowledge has been substantially increased through the high level of research activity and the ensuing debates. In addition, improved access to high-quality data through the development of databases (e.g., the Human Mortality Database, <http:// www.mortality.org/>), increased computer power, the wider (though still not sufficient) availability of specialised software (e.g., $<$ http://www.robhyndman.info/ Rlibrary/demography/>), and the (partial), adoption of $\mathrm{R}$ as the common programming language are major contributions to the development of the research environment. If little progress has so far been made along the developmental path, demographers have at least acquired many of the skills and equipment for their future progression.

\subsection{Progress in forecasting performance}

The performance of demographic forecasts is often assessed against a range of criteria taking both quantifiable and qualitative factors into account (Ahlburg, 1995; Long, 1993, 1995; McNown, Rogers, \& Little, 1995; Rogers, 1995c; Swanson \& Tayman, 1995).

For any forecast worthy of the name, accuracy is a main goal. However, as Keyfitz (1981:580) observed, accuracy was of little ex post concern to population forecasters. In fact, little is known about what makes one demographic forecasting method more accurate than another, or indeed which can reliably be so distinguished. The fact that there is no evidence that overall accuracy in mortality and fertility forecasting has improved over time (e.g., Keilman, 1997) suggests that methods per se have not become more accurate. Indeed, an oft-found conclusion is that forecast accuracy is situation-specific. Little progress has been made in advancing knowledge about which methods can be relied upon when conditions are unstable.

A difficulty for the assessment of accuracy in demographic forecasting is the length of the time horizon: long-term methods, such as the Lee-Carter method and the expert-based approach cannot be readily evaluated. This is particularly the case for the expert-based approach, because out-of-sample evaluation based on historical data cannot be used (except perhaps in well-controlled blind experiments). Nev- ertheless, evaluations are required based on both historical data and the (short) time periods that have elapsed. More comparative research focussed on methods would assist in this endeavour (e.g., Booth et al., 2005); the multivariate analysis of ex post errors (Keilman, 1997) is a useful approach.

A second criterion is accuracy in the estimation of uncertainty. Advances have been made in identifying and estimating the different sources of error in forecasts of demographic processes. However, the estimation of uncertainty remains uncertain: different methods produce different estimates, only partly because they take into account different subsets of error sources. In population forecasting, the replacement of the high-low scenarios of traditional population projections by a probabilistic prediction interval is a major advance; understanding and quantification of the propagation of error in population forecasts is an important contribution. The official agencies of some of the most statistically advanced countries are now introducing probabilistic forecasting; the Netherlands is a pioneer in this respect, and the US has recently chosen to employ formal time series modelling of the demographic components with stochastic population renewal (Long \& Hollmann, 2004). Similar developments can be expected elsewhere.

A third criterion is consistency. Multistate methods produce consistency between national and subnational population forecasts. A major advantage of fully probabilistic population forecasts is the consistency of prediction intervals for different indices. On this criterion, significant progress has been made. Other criteria for the evaluation of forecasting performance broaden the concept considerably; parsimony, facevalidity and legitimacy are largely specific to the particular method and data used. Utility has been increased by virtue of the probabilistic prediction interval and the consistency that this affords. Transparency, which is essential if new methods are to be adopted and valid comparisons are to be made, has been increased in that methods and their assumptions are now documented and extensively discussed.

A final criterion is user acceptability. Probabilistic population forecasts are often viewed as too complex to be understood by users who are accustomed to using the medium scenario of traditional population projections and appear to have no use for the high and low scenarios (Lutz \& Goldstein, 2004b). This view 
neglects the possibility that users realize the limitations of traditional population projections and simply make the best use of a poor product. Wellexplained forecasts with probabilistic prediction intervals might indeed be welcomed by users: at last they would have a user-defined probability range of population futures that are consistent, rational and valid. User acceptability requires independent evaluation, distinguishing it from the "reluctance of forecasters to make the leap from using scenarios to fully stochastic forecasts" (Goldstein, 2004:94).

By most criteria, therefore, forecasting performance has been improved over the period under review. Only accuracy remains essentially unchanged, or in the longer-term unproven. Thus, the improvement of forecast accuracy and the concomitant reduction of uncertainty remains an important focus for research. Greater certainty in the estimation of uncertainty is also an ongoing aim.

\subsection{Competition, combination and complementarity}

Improving the accuracy of demographic forecasting is a major challenge. Two ideas borrowed from forecasting in other disciplines are competition and combining. Competition in demographic forecasting has been both advocated and criticised. Land (1986), Ahlburg and Vaupel (1990), Ahlburg (1995) and Rogers (1995c) advocated livelier competition or formal tournaments to compare forecasting accuracy. The idea was short-lived, however, perhaps because of the focus on uncertainty and the lack of both a passionate advocate and an appropriate institutional backing. Ahlburg and Lutz (1999:5) found the emergence of informal competition characterised by "a struggle for the survival of the fittest model, where fitness is judged primarily by forecast accuracy... .or by the strength of the institution behind the forecast to be counterproductive." Ahlburg et al. (1999:192) regard any exercise aiming "to find the best method" as "futile."

Combining has not fared any better. The combining of forecasts from different models involves averaging or some other procedure as a simple and pragmatic way to possibly produce better forecasts (Granger, 1989, 2001), and has been repeatedly advocated as a means of increasing the accuracy of demographic forecasts (Ahlburg, 1995; Ahlburg \& Land, 1992b; Ahlburg \& Lutz, 1999; Willekens, 1992). However, the idea has not been embraced. In rare exceptions, De Beer (1988) found combining to be advantageous only in the very short term, while Sanderson (1999) found it beneficial for forecasting the rate of natural increase. It is noted that probabilistic consistency would be forfeited if cohort-component-based population forecasts were combined.

While combining per se has not found favour, complementarity is increasingly recognised (e.g., Tuljapurkar et al., 2004:198). In forecasting demographic processes, the complementary combination of useful aspects of approaches would appear to be more fruitful than trying to find a single best method or combining forecasts from competing approaches. As has already been noted (Section 5.7), recent research has emphasised the complementarity of approaches at least as far as the estimation of uncertainty is concerned (e.g., Alders \& De Beer, 2004). This pragmatic complementary approach avoids the complications involved in combining the prediction intervals of competing forecasts (Granger, 2001); it also facilitates the more complete estimation of uncertainty than a single approach might permit.

Complementarity has also been adopted in population forecasting; several methods combine probabilistic forecasts with the scenario approach. In the modified scenario approach (Goldstein, 2004), traditional population projections are calibrated to stochastic forecasts by adopting the prediction limits of life expectancy and average fertility forecasts as high and low assumptions, achieving similarity of population uncertainty estimates (adjustment is needed in the case of ratios). Conditional probabilistic population forecasting takes various forms. One such method involves classifying simulated population trajectories according to their randomly-generated fertility and mortality levels, permitting what-if questions to be examined (Sanderson, Scherbov, O’Neill, \& Lutz, 2004); applications include Lutz and Scherbov (2002) and O'Neill (2004). Another method involves classifying forecasts according to the level of the forecast after an initial period, thus addressing policy questions about whether to delay action (Sanderson et al., 2004).

\subsection{Forecasting demographic change}

In order to improve forecast accuracy, methods are needed that have the capacity to capture structural 
change. Both the period-specificity of forecast accuracy and the lack of improvement stem from the inadequacy of existing methods to forecast change. Extrapolative time series methods, such as the LeeCarter method, do not purport to forecast structural change but produce wide prediction intervals that encompass variability from past change.

Neither does the expert-based approach claim to forecast structural change; Lutz, Goldstein, et al. (1996) merely state a belief that structural change is likely to happen (p. 38) and that in determining the predictive probability distribution, experts can 'consider possible alternative stories that might happen in the future' (p. 37). In practice, in this approach change is expressed only as an aggregate target in a specific year; the timing of change is not predicted, nor is the age pattern permitted to change. If this approach is to better predict change, it must be further developed to incorporate the timing of changes in trends and to formalise the decision-making processes involved in making use of demographic knowledge, perhaps through some form of model incorporating expertbased quantified effects. The wide availability of standardised survey data (e.g., Demographic and Health Surveys) facilitates such modelling.

There is no doubt that our capacity to forecast demographic change will gain from a greater understanding of the causal factors and processes that determine the level, sequence and timing of demographic events, as Willekens (1990) affirmed. Significant progress has in fact been made over the last twenty-five years in increasing such understanding. However, this has not resulted in theory-informed forecasting; current demographic theory is too general to be of such use. Rather, it would appear that demographic behaviour, like most human behaviour, is too complex to be easily modelled and forecast; indeed, it may be inherently unpredictable. Only mortality, which is largely biological, lends itself at all to an explanatory structural approach.

The complexity of demographic behaviour would suggest that disaggregation and decomposition is an appropriate and potentially useful approach, at least in the short- to medium-term. The increased understanding of demographic life-course processes and their determinants, combined with increased computer power, facilitates added dimensions of disaggregation and decomposition and the development of both increasingly detailed multistate (macrosimulation) models and individual-level microsimulation.

The new European MicMac project combines the macrosimulation and microsimulation approaches to produce forecasts of both the population in multidimensional states (defined by age, sex and various other statuses such as participation in the labour force) and the length of time spent in those states (Van der Gaag, De Beer, \& Willekens, 2005; Willekens, 2005; Willekens, De Beer, \& Van der Gaag, 2005). The macrosimulation involves the construction of cohort biographies at the population level, while the microsimulation produces synthetic individual biographies which are aggregated to determine population characteristics. The bridge between the cohort and individual biographies is the common use of transition rates estimated conditionally on covariates (occurrenceexposure rates); thus the dynamics at the macro- and micro-levels are internally consistent. Informed by an increased understanding of demographic processes, transition rates are modelled and forecast either by regressions (structural models) or by recourse to (further) disaggregation. Thus, structural modelling is being incorporated into demographic forecasting. The MicMac approach is complementary and pragmatic: it makes use of causality where possible, and otherwise of statistical association. Further complementarity is likely to be found in the estimation of uncertainty and in the methodological details.

It remains to be seen to what extent MicMac will improve forecast accuracy by capturing structural change. This depends in part on the validity of the causal models. How can the theory embedded in these models be tested and further theory developed? One approach is to make use of agent-based or behavioural modelling; this differs from empiricallybased microsimulation in that the computational model is based on pre-defined behavioural rules. Agent-based computational models simulate feedbacks and behavioural hypotheses, as can microsimulation, but the purpose is to verify whether the rules of individual behaviour can produce macrolevel regularities and variability (e.g. Murphy, 2003); thus theory is tested and developed. Though agentbased computational methods have only recently been explored in demography (Billari \& Prskawetz, 2003), they have the potential to assist in the development of demographic behavioural theory 
and thus to contribute to progress along the path towards forecasting demographic change.

\section{Acknowledgments}

Thanks to Vanessa Frame for bibliographic assistance, and to Bruce Bacon, John Maindonald and two anonymous reviewers for useful comments and additional material.

\section{References}

Ahlburg, D. A. (1982). How accurate are the U.S. Bureau of the Census projections of total live births? Journal of Forecasting, 1, 365-374.

Ahlburg, D. A. (1983). Good times, bad times: A study of the future path of US fertility. Social Biology, 30, 17-23.

Ahlburg, D. A. (1986). A relative cohort size forecasting model of Canadian total live births. Social Biology, 30, 51-56.

Ahlburg, D. A. (1987a). Modeling macroeconomic-demographic linkages: A study of models of national and regional economies. In K. Land, \& S. Schneider (Eds.), Forecasting in the natural and social sciences (pp. 287-336).

Ahlburg, D. A. (1987b). Population forecasts for South Pacific nations using autoregressive models. Journal of the Australian Population Association, 4, 157-167.

Ahlburg, D. A. (1995). Simple versus complex models: Evaluation, accuracy, and combining. Mathematical Population Studies, 5, $281-290$.

Ahlburg, D. A., \& Land, K. C. (Eds.) (1992a). International Journal of Forecasting, 8, issue 3.

Ahlburg, D. A., \& Land, K. C. (1992b). Population forecasting: Guest editors' introduction. International Journal of Forecasting, 8, 289-299.

Ahlburg, D. A., \& Lutz, W. (1999). Introduction: The need to rethink approaches to population forecasts. In W. Lutz, J. W. Vaupel (Eds.), Frontiers of population forecasting (pp. 1-14). New York: Population Council. A supplement to Population and Development Review, Volume 24, 1998.

Ahlburg, D. A., Lutz, W., \& Vaupel, J. W. (1999). Ways to improve population forecasting: What should be done differently in the future? In W. Lutz, J. W. Vaupel (Eds.), Frontiers of population forecasting (pp. 191-198). New York: Population Council. A supplement to Population and Development Review, Volume 24, 1998.

Ahlburg, D. A., \& Vaupel, J. W. (1990). Alternative projections of the U.S. population. Demography, 27, 639-652.

Alders, M., \& De Beer, J. (2004). Assumptions on fertility in stochastic population forecasts. International Statistical Review, $72,65-79$.

Alders, M., \& De Beer, J. (2005). An expert knowledge approach to stochastic mortality forecasting in the Netherlands. In $\mathrm{N}$. Keilman (Ed.), Perspectives on mortality forecasting. Probabi- listic models, vol. II (pp. 39-64). Stockholm: Swedish Social Insurance Agency.

Alho, J. M. (1990). Stochastic methods in population forecasting. International Journal of Forecasting, 6, 521-530.

Alho, J. M. (1991). Effect of aggregation on the estimation of trend mortality. Mathematical Population Studies, 2, 53-67.

Alho, J. M. (1992a). The magnitude of error due to different vital processes in population forecasts. International Journal of Forecasting, 8, 301-314.

Alho, J. M. (1992b). Estimating the strength of expert judgement: The case of US mortality forecasts. Journal of Forecasting, 11 , $157-167$.

Alho, J. M. (1997). Scenarios, uncertainty and conditional forecasts of the world population. Journal of the Royal Statistical Society. Series A, 160, 71-85.

Alho, J. M. (1998). A stochastic forecast of the population of Finland (reviews no. 1998/4). Helsinki: Statistics Finland.

Alho, J. M. (2003). Experiences from forecasting mortality in Finland. In T. Bengtsson, \& N. Keilman (Eds.), Perspectives on mortality forecasting. Current practice, vol. I (pp. 29-40). Stockholm: Swedish Social Insurance Agency.

Alho, J. M. (2005). Remarks on the use of probabilities in demography and forecasting. In N. Keilman (Ed.), Perspectives on mortality forecasting. Probabilistic models, vol. II (pp. 27-38). Stockholm: Swedish Social Insurance Agency.

Alho, J. M., \& Nyblom, J. (1997). Mixed estimation of old-age mortality. Mathematical Population Studies, 6, 319-330.

Alho, J. M., \& Spencer, B. D. (1985). Uncertain population forecasting. Journal of the American Statistical Association, 80, $306-314$.

Alho, J. M., \& Spencer, B. D. (1990a). Error models for official mortality forecasts. Journal of the American Statistical Association, 85, 609-616.

Alho, J. M., \& Spencer, B. D. (1990b). Effects of targets and aggregation on the propagation of error in mortality forecasts. Mathematical Population Studies, 2, 209-227.

Alho, J. M., \& Spencer, B. D. (1991). A population forecast as a database: Implementing the stochastic propagation of error Journal of Official Statistics, 7, 295-310.

Alho, J. M., \& Spencer, B. D. (1997). The practical specification of the expected error of population forecasts. Journal of Official Statistics, 13, 203-225.

Alho, J. M., \& Spencer, B. D. (2005). Statistical demography and forecasting. New York: Springer.

Ashley, R. (1983). On the usefulness of macroeconomic forecasts as inputs to forecasting models. Journal of Forecasting, 2, $211-223$.

Auvert, B. (1991). The Auvert approach: A stochastic model for the heterosexual spread of the human immunodeficiency virus. The AIDS epidemic and its demographic consequences (pp. 77-83). New York and Geneva: United Nations/World Health Organization.

Bell, W. (1992). ARIMA and principal component models in forecasting age-specific fertility. In N. Keilman, \& H. Cruijsen (Eds.), National population forecasting in industrialized countries (pp. 178-200). Amsterdam: Swets and Zeitlinger. 
Bell, W. (1997). Comparing and assessing time series methods for forecasting age-specific fertility and mortality rates. Journal of Official Statistics, 13, 279-303.

Bell, W. R., \& Monsell, B. C. (1991). Using principal components in time series modeling and forecasting of age-specific mortality rates. Paper presented at the American Statistical Association 1991 Proceedings of the Social Statistics Section.

Bengtsson, T., \& Keilman, N. (Eds.) (2003). Perspectives on mortality forecasting. Current practice, vol. IX. Stockholm: Swedish National Social Insurance Board.

Bijak, J., Kupiszewski, M., \& Kicinger, A. (2004). International migration scenarios for 27 European countries, 2002-2052 (Working Paper 4/2004). Warsaw: Central European Forum for Migration Research.

Billari, F., \& Prskawetz A. (Eds.) (2003). Agent-based computational demography: Using simulation to improve our understanding of demographic behaviour. Heidelberg: PhysicaVerlag.

Bloom, D. E. (1982). What's happening to the age at first birth in the United States? A study of recent cohorts. Demography, 19, $351-370$.

Bloom, D. E., \& Glied, S. (1992). Projecting the number of new AIDS cases in the United States. International Journal of Forecasting, 8, 339-365.

Bloom, D. E., \& Trussell, J. (1984). What are the determinants of delayed childbearing and permanent childlessness in the United States? Demography, 21, 591-611.

Boleslawski, L., \& Tabeau, E. (2001). Comparing theoretical age patterns of mortality beyond the age of 80 . In E. Tabeau, A. Van Den Berg Jeths, \& C. Heathcote (Eds.), Forecasting mortality in developed countries: Insights from a statistical, demographic and epidemiological perspective (pp. 127-155). Dordrecht: Kluwer Academic Publishers.

Bongaarts, J. (1989). A model of the spread of HIV infection and the demographic impact of AIDS. Statistics in Medicine, 8 , $301-308$.

Bongaarts, J. (2005). Long-range trends in adult mortality: Models and projection methods. Demography, 42, 23-49.

Bongaarts, J., \& Bulatao, R. A. (1999). Completing the demographic transition. Population and Development Review, 25, $515-529$.

Bongaarts, J., \& Bulatao R. A. (Eds.) (2000). Beyond six billion: Forecasting the world's population. Washington, DC: National Academy Press.

Bongaarts, J., \& Feeney, G. (1998). On the quantum and tempo of fertility. Population and Development Review, 24, 271-291.

Bongaarts, J., \& Feeney, G. (2002). How long do we live? Population and Development Review, 28, 13-29.

Bongaarts, J., \& Feeney, G. (2003). Estimating mean lifetime. Proceedings of the National Academy of Sciences, 100, $13127-13133$.

Bongaarts, J., \& Feeney, G. (2005). The quantum and tempo of lifecycle events (Working Paper No. 207). New York: Population Council.

Booth, H., Maindonald, J., \& Smith, L. (2001). Age-time interactions in mortality projection: Applying Lee-Carter to
Australia (Working Papers in Demography No. 85). Canberra: Australian National University.

Booth, H., Maindonald, J., \& Smith, L. (2002). Applying LeeCarter under conditions of variable mortality decline. Population Studies, 56, 325-336.

Booth, H., Tickle, L., \& Smith, L. (2005). Evaluation of the variants of the Lee-Carter method of forecasting mortality: A multicountry comparison. New Zealand Population Review, Special Issue on Stochastic Population Projections (edited by A. Dharmalingam and I. Pool), 31, 13-37.

Bos, E., \& Bulatao, R. (1992). The demographic impact of AIDS in sub-Saharan Africa: Short and long-term projections. International Journal of Forecasting, 8, 367-384.

Box, G. E. P., \& Jenkins, G. M. (1976). Time series analysis: Forecasting and control (Revised Edition). Englewood Cliffs, N.J.: Prentice Hall.

Bozik, J. E., \& Bell, W. R. (1987). Forecasting age specific fertility using principal components. Paper presented at the Proceedings of the Social Statistics Section, American Statistical Association, San Francisco, California.

Brass, W. (1971). On the scale of mortality. In W. Brass (Ed.), Biological aspects of demography (pp. 69-110). London: Taylor and Francis.

Brass, W. (1974). Perspectives in population prediction: Illustrated by the statistics of England and Wales. Journal of the Royal Statistical Society Series A, 137, 532-583.

Brass, W. (1981). The use of the Gompertz relational model to estimate fertility. International Population Conference, Manila, vol. 3 (pp. 345-362).

Brooks, C., Sams, D., \& Williams, P. (1980). A time series of smooth approximations for age, sex, and marital status specific death rates in Australia, 1950/1951 to 1975/1976, with projections to the year 2000. Melbourne, Australia: Research memorandum: Impact projection research centre.

Brouhns, N., Denuit, M., \& Vermunt, J. K. (2002). A Poisson logbilinear regression approach to the construction of projected lifetables. Insurance: Mathematics and Economics, 31, 373-393.

Buettner, T. (2002). Approaches and experiences in projecting mortality patterns for the oldest-old. North American Actuarial Journal, 6, 14-29.

Buettner, T., \& Zlotnik, H. (2005). Prospects for increasing longevity as assessed by the United Nations. Genus, 213-233.

Bulatao, R. A. (1991). The Bulatao approach: Projecting the demographic impact of the HIV epidemic using standard parameters. The AIDS epidemic and its demographic consequences, (pp. 90-104). New York and Geneva: United Nations/ World Health Organization.

Calhoun, C. A., \& De Beer, J. (1991). Birth expectations and population forecasts: The case of the Netherlands. In W. Lutz (Ed.), Future demographic trends in Europe and North America: What can we assume today? (pp. 197-226). London: Academic Press.

Carrière, J. F. (1992). Parametric models for life tables. Transactions of the Society of Actuaries, 44, 77-99.

Carter, L. R. (1996). Forecasting U.S. mortality: A comparison of Box-Jenkins ARIMA and structural time series models. The Sociological Quarterly, 37, 127-144. 
Carter, L. R. (2000). Imparting structural instability to mortality forecasts: Testing for sensitive dependence on initial conditions with innovations. Mathematical Population Studies, 8, $31-54$.

Carter, L. R., \& Lee, R. D. (1986). Joint forecasts of U.S. marital fertility, nuptiality, births and marriages using time series models. Journal of the American Statistical Association, 81, 902-911.

Carter, L. R., \& Lee, R. D. (1992). Modelling and forecasting US sex differentials in mortality. International Journal of Forecasting, 8, 393-411.

Carter, L. R., Prskawetz, A. (2001). Examining structural shifts in mortality using the Lee-Carter method (MPIDR Working Paper No. WP 2001-007): Max Planck Institute for Demographic Research.

Caselli, G. (1996). Future longevity among the elderly. In G. Caselli \& A. Lopez (Eds.), Health and mortality among elderly populations. Oxford: Clarendon Press.

Caselli, G. (2002). Age, period and cohort components in analysing past and projecting future mortality trends. In G. Wunsch, M. Mouchart, \& J. Duchene (Eds.), The life table: Modelling survival and death (pp. 117-140). Dordrecht: Kluwer Academic Publishers.

Chandola, T., Coleman, D. A., \& Hiorns, R. W. (1999). Recent European fertility patterns: Fitting curves to 'distorted' distributions. Population Studies, 53, 317-329.

Chandola, T., Coleman, D. A., \& Hiorns, R. W. (2000). A reply to J. Antonio Ortega Osona and H. P. Kohler. Population Studies, 54,351 .

Chauhan, R. K. (1997). Graduation of infant deaths by age. Demography India, 26, 261-274.

Chen, R., \& Morgan, S. P. (1991). Recent trends in the timing of first births in the United States. Demography, 28, 513-533.

Coale, A. J., Demeny, P. G., \& Vaughan, B. (1983). Regional model life tables and stable populations (2nd ed.). New York: Academic Press.

Coale, A. J., \& Guo, G. (1989). Revised regional model life tables at very low levels of mortality. Population Index, 55, $613-643$.

Coale, A. J., \& Kisker, E. E. (1990). Defects in data on old-age mortality in the United States: New procedures for calculating schedules and life tables at the highest ages. Asian and Pacific Population Forum, 4, 1-31.

Coale, A. J., \& McNeil, D. R. (1972). The distribution by age of the frequency of first marriage in a female cohort. Journal of the American Statistical Association, 67, 743-749.

Coale, A. J., \& Trussell, T. J. (1974). Model fertility schedules: Variations in the age structure of childbearing in human populations. Population Index, 40, 185-258.

Cohen, J. E. (1986). Population forecasts and confidence intervals for Sweden: A comparison of model-based and empirical approaches. Demography, 23, 105-126.

Cohen, J. E. (1999). Should population projections consider "limiting factors" - And if so how? In W. Lutz, J. W. Vaupel, \& D. A. Ahlburg (Eds.), Frontiers of population forecasting (pp. 118-138). New York: Population Council. A supplement to Population and Development Review vol. 24 (1998).
Congdon, P. (1980). Forecasting births in greater London: An application of the Easterlin hypothesis. Population Studies, 34, 267-278.

Congdon, P. (1989). Fertility forecasts and structural interpretations: An application to London and England and Wales. Espaces, Populations et Sociétés, 1989-2, 177-188.

Congdon, P. (1990). Graduation of fertility schedules: An analysis of fertility patterns in London in the 1980s and an application to fertility forecasts. Regional Studies, 24, 311-326.

Congdon, P. (1993). Statistical graduation in local demographic analysis and projection. Journal of the Royal Statistical Society, $156,237-270$.

Crimmins, E. M. (1981). The changing pattern of American mortality decline, 1947-1977, and its implication for the future. Population and Development Review, 7, 229-254.

Cruijsen, H., \& Eding, H. (2001). The latest mortality forecasts in the European Union. In E. Tabeau, A. Van Den Berg Jeths, \& C. Heathcote (Eds.), Forecasting mortality in developed countries: Insights from a statistical, demographic and epidemiological perspective (pp. 227-258). Dordrecht: Kluwer Academic Publishers.

Currie, D., Durban, M., \& Eilers, P. H. C. (2004). Smoothing and forecasting mortality rates. Statistical Modelling, 4, 279-298.

De Beer, J. (1985). A time series model for cohort data. Journal of the American Statistical Association, 80, 525-530.

De Beer, J. (1988). Predictability of demographic variables in the short run. European Journal of Population, 4, 283-296.

De Beer, J. (1989). Projecting age-specific fertility rates by using time-series methods. European Journal of Population, 5 , 315-346.

De Beer, J. (1991). From birth expectations to birth forecasts: A partial adjustment approach. Mathematical Population Studies, 3, $1127-1144$.

De Beer, J. (1997). The effect of uncertainty of migration on national population forecasts: The case of the Netherlands. Journal of Official Statistics, 13, 227-243.

De Beer, J. (2000). Dealing with uncertainty in population forecasting: Statistics Netherlands, Department of Population.

De Beer, J., \& Alders, M. (1999). Probabilistic population and household forecasts for the Netherlands. Working Paper No. 45. Paper presented at the Joint ECE-Eurostat Work Session on Demographic Projections, 3-7 May 1999, Perugia, Italy.

De Beer, J., \& Van Wissen, L. (Eds.) (1999). Europe: One continent, different worlds; population scenarios for the 21st century. Dordrecht: Kluwer.

De Cooman, E., Ermisch, J., \& Joshi, H. (1987). The next birth and the labour market: A dynamic model of births in England and Wales. Population Studies, 41, 237-268.

De Gans, H. A. (1999). Population forecasting 1895-1945: The transition to modernity. Dordrecht: Kluwer Academic.

De Jong, P., \& Tickle, L. (2006). Extending Lee-Carter mortality forecasting. Mathematical Population Studies, 13, $1-18$.

Easterlin, R. A. (1968). Population, labour force, and long swings in economic growth: The America experience. General series, vol. 86. .New York: National Bureau of Economic Research. 
Edwards, R., \& Tuljapurkar, S. (2005). Inequality in life spans and a new perspective on mortality convergence across industrialized countries. Population and Development Review, 31, 645-675.

Ermisch, J. (1983). The political economy of demographic change: Causes and implications of population trends in Great Britain. London: Heinemann.

Ermisch, J. (1988). Econometric analysis of birth rate dynamics in Britain. Journal of Human Resources, 23, 563-576.

Ermisch, J. (1992). Explanatory models for fertility projections and forecasts. In N. Keilman, \& H. Cruijsen (Eds.), National population forecasting in industrialized countries (pp. 201-222). Amsterdam: Swets and Zeitlinger.

Evans, M. D. R. (1986). American fertility patterns: A comparison of white and nonwhite cohorts born 1903-56. Population Development Review, 12, 267-293.

Ewbank, D. C., Gómez De León, J. C., \& Stoto, M. A. (1983). A reducible four-parameter system of model life tables. Population Studies, 37, 105-127.

Forfar, D. O., McCutcheon, M. A., \& Wilkie, A. D. (1988). On graduation by mathematical formula. Journal of the Institute of Actuaries, 115, 97-245.

Forfar, D. O., \& Smith, D. M. (1987). The changing face of English life tables. Transactions of the Faculty of Actuaries, 40, $98-134$.

Gage, T. B., \& Mode, C. J. (1993). Some laws of mortality: How well do they fit? Human Biology, 65, 445-461.

Gavrilov, L. A., \& Gavrilova, N. S. (1991). The biology of life span. A quantitative approach. Chur, NY: Harwood Academic Publishers.

George, M. V. (1994). Population projections for Canada, provinces and territories: 1993-2016. Ottawa: Statistics Canada.

George, M. V., \& Perreault, J. (1992). Methods of external migration projections and forecasts. In N. Keilman, \& H. Cruijsen (Eds.), National population forecasting in industrialized countries (pp. 87-103). Amsterdam: Swets and Zeitlinger.

Girosi, F., \& King, G. (2006). Demographic forecasting. Cambridge: Cambridge University Press.

Goldstein, J. R. (2004). Simpler probabilistic population forecasts: Making scenarios work. International Statistical Review, 72, 93-106.

Goldstein, J. R., \& Stecklov, G. (2002). Long-range population projections made simple. Population and Development Review, $28,121-141$.

Golulapati, R., De Ravin, J. W., \& Trickett, P. J. (1984). Projections of Australian mortality rates, 1981-2020 (occasional paper no. 1983/2). Australian Bureau of Statistics.

Gómez de León, J. (1990). Empirical DEA models to fit and project time series of age-specific mortality rates. Oslo, Norway: Central Bureau of Statistics. Unpublished manuscript.

Goss, S. C., Wade, A., Bell, F., \& Dussault, B. (1998). Historical and projected mortality for Mexico, Canada, and the United States. North American Actuarial Journal, 2, 108-128.

Granger, C. W. (1989). Invited review: Combining forecasts Twenty years later. Journal of Forecasting, 8, 167-173.

Granger, C. W. (2001). Invited review: Combining forecasts - Twenty years later. In E. Ghysels, N. R. Swanson, \& M. W. Watson (Eds.), Essays in econometrics: Spectral analysis, seasonality, nonlinearity, methodology, and forecasting (pp. 411-419). New York: Cambridge University Press.

Guillot, M. (2003). The cross-sectional average length of life (CAL): A period mortality measure that reflects the experience of cohorts. Population Studies, 57, 41-54.

Gutterman, S., \& Vanderhoof, I. T. (1998). Forecasting changes in mortality: A search for a law of causes and effects. North American Actuarial Journal, 2, 135-138.

Hannerz, H. (1999). Methodology and applications of a new law of mortality. Lund: Department of Statistics, University of Lund, Sweden.

Hannerz, H. (2001a). Presentation and derivation of a five-parameter survival function intended to model mortality in modern female populations. Scandinavian Actuarial Journal, 2001, 176-187.

Hannerz, H. (2001b). Manhood trials and the law of mortality. Demographic Research, 4, 185-202.

Hannerz, H. (2001c). An extension of relational methods in mortality estimation. Demographic Research, 4, 337-367.

Hartmann, M. (1987). Past and recent attempts to model mortality at all ages. Journal of Official Statistics, 3, 19-36.

Hauser, R. M., \& Willis, R. J. (2005). Survey design and methodology in the Health and Retirement Study and the Wisconsin Longitudinal Study. In L.J. Waite (Ed.), Aging, health, and public policy: Demographic and economic perspectives. Supplement to Population and Development Review, vol. 30. (pp. 209-235). New York: Population Council 2004.

Heathcote, C., \& Higgins, T. (2001a). Forecasting mortality from regression models: The case of the Netherlands. In E. Tabeau, A. Van Den Berg Jeths, \& C. Heathcote (Eds.), Forecasting mortality in developed countries: Insights from a statistical, demographic and epidemiological perspective (pp. 83-103). Dordrecht: Kluwer Academic Publishers.

Heathcote, C., \& Higgins, T. (2001b). A regression model of mortality, with applications to the Netherlands. In E. Tabeau, A. Van Den Berg Jeths, \& C. Heathcote (Eds.), Forecasting mortality in developed countries: Insights from a statistical, demographic and epidemiological perspective (pp. 59-82). Dordrecht: Kluwer Academic Publishers.

Heckman, J. J., \& Walker, J. R. (1989). Forecasting aggregate period-specific birth rates: The time series properties of a microdynamic neoclassical model of fertility. Journal of the American Statistical Association, 84, 958-965.

Heligman, L., \& Pollard, J. H. (1980). The age pattern of mortality. Journal of the Institute of Actuaries, 107, 49-80.

Hendershot, G. E., \& Placek, P. J. (Eds.) (1981). Predicting fertility: Demographic studies of birth expectations. Lexington, MA: Lexington.

Hilderink, H., Van der Gaag, N., Van Wissen, L., Jennissen, R., Román, A., \& Salt, J., et al. (2002). Analysis and forecasting of international migration by major groups. Part III (working papers and studies no. 3/2002/E/n17). The Hague: Eurostat.

Himes, C. L., Preston, S. H., \& Condran, G. A. (1994). A relational model of mortality at older ages in low mortality countries. Population Studies, 48, 269-291.

Hoem, J. M., Madsen, D., Nielsen, J. L., Ohlsen, E. M., Hansen, H. O., \& Rennermalm, B. (1981). Experiments in modelling in recent Danish fertility curves. Demography, 18, 231-244. 
Howe, N., \& Jackson, R. (2005). Projecting immigration: A survey of the current state of practice and theory (a report of the CSIS Global Aging Initiative). Washington DC: Center for Strategic and International Studies.

Hyndman, R. J., \& Ullah, S. (2004). Robust forecasting of mortality and fertility rates: A functional data approach (working paper). Melbourne: Monash University.

Kaneko, R. (2003). Elaboration of the Coale-McNeil nuptiality model as the generalized log gamma distribution: A new identity and empirical enhancements. Demographic Research, 9, 223-262.

Kannisto, V. (1994). Development of oldest-old mortality, 19501990: Evidence from 28 developed countries. Odense, Denmark: Odense University Press.

Kannisto, V., Lauritsen, J., Thatcher, A. R., \& Vaupel, J. W. (1994). Reductions in mortality at advanced ages: Several decades of evidence from 27 countries. Population and Development Review, 20, 793-810.

Keilman, N. (1990). Uncertainty in population forecasting: Issues, backgrounds, analyses, recommendations. Amsterdam: Swets and Zeitlinger.

Keilman, N. (1997). Ex-post errors in official population forecasts in industrialized countries. Journal of Official Statistics, 13, $245-277$.

Keilman, N. (1999). How accurate are the United Nations world population projections? In W. Lutz, J. W. Vaupel, \& D. A. Ahlburg (Eds.), Frontiers of population forecasting. A supplement to Population and Development Review, vol. 24 (pp. 15-41). New York: Population Council.

Keilman, N. (2001a). Uncertain population forecasts. Nature, 412, 490-491.

Keilman, N. (2001b). Data quality and accuracy of United Nations population projections, 1950-95. Population Studies, $55,149-164$.

Keilman, N. (2002). TFR predictions based on Brownian motion theory. Yearbook of Population Research in Finland, 38, 207-219.

Keilman, N. (Ed.) (2005a). Perspectives on mortality forecasting. Probabilistic models, vol. II. Stockholm: Swedish Social Insurance Agency.

Keilman, N. (2005b). Erroneous population forecasts. In N. Keilman (Ed.), Perspectives on mortality forecasting. Probabilistic models, vol. II (pp. 7-26). Stockholm: Swedish Social Insurance Agency.

Keilman, N., \& Pham, D. Q. (2000). Predictive intervals for age-specific fertility. European Journal of Population, 16, $41-65$.

Keilman, N., \& Pham, D. Q. (2004). Time series based errors and empirical errors in fertility forecasts in the Nordic countries. International Statistical Review, 72, 5-18.

Keilman, N., Pham, D. Q., \& Hetland, A. (2002). Why population forecasts should be probabilistic - Illustrated by the case of Norway. Demographic Research, 6, 409-453.

Keyfitz, N. (1972). On population forecasting. Journal of the American Statistical Association, 67, 347-363.

Keyfitz, N. (1981). The limits of population forecasting. Population and Development Review, 7, 579-593.
Keyfitz, N. (1982a). Can knowledge improve forecasts? Population and Development Review, 8, 729-751.

Keyfitz, N. (1982b). Choice of function for mortality analysis: Effective forecasting depends on a minimum parameter representation. Theoretical Population Biology, 21, $329-352$.

Keyfitz, N. (1985). Demography in the twenty-first century: The uses of forecasting. International Population Conference, Florence, vol. 1 (pp. 59-81). Liège: International Union for the Scientific Study of Population.

Keyfitz, N. (1991). Experiments in the projection of mortality. Canadian Studies in Population, 18, 1-17.

Keyfitz, N. (1996). Foreword. In W. Lutz (Ed.), The future population of the world: What can we assume today? (Revised Edition). London: Earthscan.

Knudsen, C., McNown, R., \& Rogers, A. (1993). Forecasting fertility: An application of time series methods to parameterized model schedules. Social Science Research, 22, 1-23.

Kohler, H. -P., \& Ortega, J. A. (2002). Tempo-adjusted period parity progression measures, fertility postponement and completed cohort fertility. Demographic Research, 6, 91-144.

Kohler, H. -P., \& Philipov, D. (2001). Variance effects in the Bongaarts-Feeney formula. Demography, 38, 1-16.

Kostaki, A. (1988). Contributions to the methodology and application of the Heligman-Pollard formula. Lund: University of Lund.

Kostaki, A. (1992). A nine parameter version of the HeligmanPollard formula. Mathematical Population Studies, 3, 277-288.

Kunst, A. E., Mackenbach, J. P., Lautenbach, H., Oei, F. B., \& Bijlsma, F. (2002). Gains in life expectancy by eliminating major causes of death: Revised estimates taking into account competing causes of death. In G. Wunsch, M. Mouchart, \& J. Duchene (Eds.), The life table: Modelling survival and death (pp. 191-207). Dordrecht, The Netherlands: Kluwer Academic Publishers.

Land, K. C. (1986). Methods for national population forecasts: A review. Journal of the American Statistical Association, 81, $888-901$.

Le Bras, H. (2005). Mortality tempo versus removal of causes of mortality: Opposite views leading to different estimations of life expectancy. Demographic Research, 13, 615-640.

Leach, D. (1981). Re-evaluation of the logistic curve for human populations. Journal of the Royal Statistical Society. Series A, 144, 94-103.

Lee, R. D. (1974). Forecasting births in post-transition populations: Stochastic renewal with serially correlated fertility. Journal of the American Statistical Association, 69, 607-617.

Lee, R. D. (1980). Aiming at a moving target: Period fertility and changing reproductive goals. Population Studies, 34, 205-226.

Lee, R. D. (1981). A model for forecasting fertility from birth expectations data. In G. E. Hendershot, \& P. J. Placek (Eds.), Predicting fertility: Demographic studies of birth expectations (pp. 75-99). Lexington, MA: Lexington.

Lee, R. D. (1990). Long-run global population forecasts: A critical appraisal. Population and Development Review, 16, 44-71.

Lee, R. D. (1992). Stochastic demographic forecasting. International Journal of Forecasting, 8, 315-327. 
Lee, R. D. (1993). Modeling and forecasting the time series of US fertility: Age distribution, range, and ultimate level. International Journal of Forecasting, 9, 187-202.

Lee, R. D. (1999). Probabilistic approaches to population forecasting. In W. Lutz, J. W. Vaupel, \& D. A. Ahlburg (Eds.), Frontiers of population forecasting. A supplement to Population and Development Review, vol. 24 (pp. 156-190). New York: Population Council.

Lee, R. D. (2000a). The Lee-Carter method for forecasting mortality, with various extensions and applications. North American Actuarial Journal, 4, 80-93.

Lee, R. D. (2000b). Long-term population projections and the US social security system. Population and Development Review, 26 , $137-143$.

Lee, R. D. (2005). Quantifying our ignorance: Stochastic forecasts of population and public budgets. In L. J. Waite (Ed.), Aging, health, and public policy: Demographic and economic perspectives. Supplement to Population and Development Review, vol. 30 (pp. 153-175). New York: Population Council.

Lee, R. D., \& Carter, L. R. (1992). Modelling and forecasting U.S. mortality. Journal of the American Statistical Association, 87, 659-671.

Lee, R. D., Carter, L. R., \& Tuljapurkar, S. (1995). Disaggregation in population forecasting: Do we need it? And how to do it simply? Mathematical Population Studies, 5, 217-234.

Lee, R. D., \& Miller, T. (2001). Evaluating the performance of the Lee-Carter method for forecasting mortality. Demography, 38 , 537-549.

Lee, R. D., \& Nault, F. (1993). Modelling and forecasting provincial mortality in Canada. Paper presented at the World Congress of the International Union of the Scientific Study of Population, Montreal. Unpublished.

Lee, R. D., \& Rofman, R. (1994). Modelacion y proyeccion de la mortalidad en Chile. NOTAS de Poblacion, XXII, 183-213.

Lee, R. D., \& Tuljapurkar, S. (1994). Stochastic population forecasts for the United States: Beyond high, medium, and low. Journal of the American Statistical Association, 89, $1175-1189$.

Lee, R. D., \& Tuljapurkar, S. (2000). Population forecasting for fiscal planning: issues and innovations. In A. Auerbach, \& R. Lee (Eds.), Demography and fiscal policy (pp. 7-57). Cambridge: Cambridge University Press.

Li, N., \& Lee, R. (2005). Coherent mortality forecasts for a group of populations: An extension of the Lee-Carter method. Demography, 42, 575-594.

Li, N., Lee, R., \& Tuljapurkar, S. (2004). Using the Lee-Carter method to forecast mortality for populations with limited data. International Statistical Review, 72, 19-36.

Li, N., \& Tuljapurkar, S. (1999). Population momentum for gradual demographic transitions. Population Studies, 53, 255-262.

Li, N., \& Tuljapurkar, S. (2000). The solution of time-dependent population models. Mathematical Population Studies, 7, $311-329$

Li, N., \& Wu, Z. (2003). Forecasting cohort incomplete fertility: A method and an application. Population Studies, 57, 303-320.

Li, S. -H., and Chan, W. -S. (2005). The Lee-Carter model for forecasting mortality revisited. Paper presented at the Living to
100 and Beyond Symposium, Orlando, Florida. Retrieved October 25, 2005 from http://ibrary.soa.org/library-pdf/m-li051_XI.pdf

Long, J. F. (1981). The utility of birth expectations in population projections. In G. E. Hendershot, \& P. J. Placek (Eds.), Predicting fertility: Demographic studies of birth expectations (pp. 29-50). Lexington, MA: Lexington.

Long, J. F. (1984). U.S. national population projections methods: A view from four forecasting traditions. Insurance, Mathematics and Economics, 3, 231-239.

Long, J. F. (1993). Accuracy, monitoring, and evaluation of national population projections. In N. Keilman, \& H. Cruijsen (Eds.), National population forecasting in industrialized countries (pp. 129-146). Amsterdam: Swets and Zeitlinger.

Long, J. F. (1995). Complexity, accuracy, and utility of official population projections. Mathematical Population Studies, 5, $203-216$.

Long, J. F., \& Hollmann, F. W. (2004). Developing official stochastic population forecasts at the US Census Bureau. International Statistical Review, 72, 201-208.

Lundstrom, H., \& Qvist, J. (2004). Mortality forecasting and trend shifts: An application of the Lee-Carter model to Swedish mortality data. International Statistical Review, 72, 37-50.

Lutz, W. (Ed.) (1996). The future population of the world: What can we assume today? (Revised ed.) London: Earthscan.

Lutz, W., \& Goldstein, J. R. (Eds.) (2004a). How to deal with uncertainty in population forecasting? Reprint of articles appearing in International Statistical Review 71(1) and $72(2)$

Lutz, W., \& Goldstein, J. R. (2004b). Introduction: How to deal with uncertainty in population forecasting? International Statistical Review, 72, 1-4.

Lutz, W., Goldstein, J. R., \& Prinz, C. (1996). Alternative approaches to population projection. In W. Lutz (Ed.), The future population of the world. What can we assume today? (pp. 14-44). London: Earthscan.

Lutz, W., Goujon, A., \& Doblhammer-Reiter, G. (1999). Demographic dimensions in forecasting: Adding education to age and sex. In W. Lutz, \& J. W. Vaupel (Eds.), Frontiers of population forecasting. A supplement to Population and Development Review, vol. 24 (pp. 42-58). New York: Population Council.

Lutz, W., Sanderson, W., \& Scherbov, S. (1996). Probabilistic population projections based on expert opinion. In W. Lutz (Ed.), The future population of the world: What can we assume today? (pp. 13-26). London: Earthscan.

Lutz, W., Sanderson, W., \& Scherbov, S. (1997). Doubling of world population unlikely. Nature, 387, 803-805.

Lutz, W., Sanderson, W., \& Scherbov, S. (1999). Expert-based probabilistic population projections. In W. Lutz, J. W. Vaupel, \& D. A. Ahlburg (Eds.), Frontiers of population forecasting. A supplement to Population and Development Review, vol. 24. (pp. 139-155). New York: Population Council.

Lutz, W., Sanderson, W., \& Scherbov, S. (2001). The end of world population growth. Nature, 412, 543-545.

Lutz, W., Sanderson, W., \& Scherbov, S. (2004). The end of world population growth. In W. Lutz, \& W. Sanderson (Eds.), The end of world population growth in the 21st century: New challenges 
for human capital formation and sustainable development (pp. 17-84). London: Earthscan.

Lutz, W., Sanderson, W., Scherbov, S., \& Goujon, A. (1996). World population scenarios for the 21 st century. In W. Lutz (Ed.), The future population of the world: What can we assume today? (pp. 361-396). London: Earthscan.

Lutz, W., \& Scherbov, S. (1998). An expert-based framework for probabilistic national population projections: The example of Austria. European Journal of Population, 14, 1-17.

Lutz, W., \& Scherbov, S. (2002). Can immigration compensate for Europe's low fertility? (Interim report no. IR-02-052). Laxenburg, Austria: IIASA.

Lutz, W., \& Scherbov, S. (2004). Probabilistic population projections for India with explicit consideration of the education-fertility link. International Statistical Review, 72, 81-92.

Lutz, W., Vaupel, J. W., \& Ahlburg, D. A. (Eds.) (1999). Frontiers of population forecasting. A supplement to Population and Development Review, vol. 24. New York: Population Council.

Manton, K. G., Patrick, C. H., \& Stallard, E. (1980). Mortality model based on delays in progression of chronic diseases: Alternative to cause elimination model. Public Health Reports, 95, 580-588.

Manton, K., Stallard, E., \& Tolley, H. D. (1991). Limits to human life expectancy: Evidence, prospects, and implications. Population and Development Review, 17, 603-637.

Manton, K. G., Stallard, E., \& Singer, B. (1992). Projecting the future size and health status of the US elderly population. International Journal of Forecasting, 8, 433-458.

Martinelle, S. (1993). The timing of first birth: Analysis and prediction of Swedish first birth rates. European Journal of Population, 9, 265-286.

McDonald, J. (1979). A time series approach to forecasting Australian total live-births. Demography, 16, 575-601.

McDonald, J. (1981). Modelling demographic relationships: An analysis of forecast functions for Australian births. Journal of the American Statistical Association, 76, 782-801.

McDonald, J. (1983). The emergence of countercyclical US fertility: A reassessment of the evidence. Journal of Macroeconomics, 5, $421-436$.

McNown, R., \& Rogers, A. (1989). Forecasting mortality: A parameterized time series approach. Demography, 26, 645-660.

McNown, R., \& Rogers, A. (1992). Forecasting cause-specific mortality using time series methods. International Journal of Forecasting, 8, 413-432.

McNown, R., Rogers, A., \& Little, J. (1995). Simplicity and complexity in extrapolative population forecasting models. Mathematical Population Studies, 5, 235-257.

Miller, R. B. (1986). A bivariate model for total fertility rate and mean age of childbearing. Insurance, Mathematics and Economics, 5, 133-140.

Miller, T. (2002). California's uncertain population future. Technical appendix for R. Lee, T. Miller \& R. D. Edwards (2003) "The Growth and Aging of California's Population: Demographic and Fiscal Projections, Characteristics and Service Needs." Available at http://repositories.cdlib.org/iber/ceda/papers/2003-0002CL/

Miller, T., \& Lee, R. (2004). A probabilistic forecast of net migration to the United States. Berkeley: Center for the Economics and Demography of Aging, University of California.
Mode, C. J., \& Busby, R. C. (1982). An eight-parameter model of human mortality - The single decrement case. Bulletin of Mathematical Biology, 44, 647-659.

Mode, C. J., \& Jacobson, M. E. (1984). A parametric algorithm for computing model period and cohort human survival functions. International Journal of Biomedical Computing, 15, 341-356.

Morgan, S. P. (1981). Intention and uncertainty at later stages of childbearing: The United States 1965 to 1970. Demography, 18, 267-285.

Morgan, S. P. (1982). Parity-specific fertility intentions and uncertainty: The United States 1970 to 1976. Demography, 19, 315-334.

Morgan, S. P. (2001). Should fertility intentions inform fertility forecasts? Proceedings of US Census Bureau Conference: The direction of fertility in the United States. Washington, DC: US Census Bureau.

Morgan, S. P., \& Chen, R. (1992). Predicting childlessness for recent cohorts of American women. International Journal of Forecasting, 8, 477-493.

Murphy, M. J. (1982). Gompertz and Gompertz relational models for forecasting fertility: An empirical exploration. London School of Hygiene and Tropical Medicine. London: Centre for Population Studies.

Murphy, M. J. (1984). Population forecasting: Alternative approaches (occasional papers). London: Office of Population Censuses and Surveys.

Murphy, M. J. (1990). Methods of forecasting mortality for population projections. Population projections: Trends, methods and uses. Occasional paper, vol. 38 (pp. 87-102). London: OPCS.

Murphy, M. J. (1995). The prospect of mortality: England and Wales and the United States of America, 1962-1989. British Actuarial Journal, 1, 331-350.

Murphy, M. J. (2003). Bringing behavior back into micro-simulation: Feedback mechanisms in demographic models. In Agent-based computational demography: Using simulation to improve our understanding of demographic behaviour (pp. 159-174). Heidelberg: Physica-Verlag.

Ní Bhrolcháin, M. (1992). Period paramount? A critique of the cohort approach to fertility. Population and Development Review, 18, 599-629.

Noack, T., \& Østby, L. (1985). Fertility expectations: A short cut or dead-end in predicting fertility? Proceedings of the seventh Nordic demographic symposium. June 1984, Paimio, Finland. Scandinavian population studies, vol. 7 (pp. 48-59). Helsinki: The Scandinavian Demographic Society.

North American Actuarial Journal (1999). Special issue on mortality forecasting, 2(4).

Oliveira, M. M., \& Mexia, J. T. (2004). AIDS in Portugal: Endemic versus epidemic forecasting scenarios for mortality. International Journal of Forecasting, 20, 131-135.

Olshansky, S. J. (1987). Simultaneous/multiple cause-delay (SIM$\mathrm{CAD})$ : An epidemiological approach to projecting mortality. Journal of Gerontology, 42, 358-365.

Olshansky, S. J. (1988). On forecasting mortality. The Milbank Quarterly, 66, 482-530.

Olshansky, S. J., \& Carnes, B. A. (1997). Ever since Gompertz. Demography, 34, 1-15. 
O’Neill, B. C. (2004). Conditional probabilistic population projections: An application to climate change. International Statistical Review, 72, 167-184.

Ortega, J. A., \& Poncela, P. (2005). Joint forecasts of Southern European fertility rates with non-stationary dynamic factor models. International Journal of Forecasting, 21, $539-550$.

Pflaumer, P. (1988). Confidence intervals for population projections based on Monte Carlo methods. International Journal of Forecasting, 4, 135-142.

Pflaumer, P. (1992). Forecasting US population totals with the BoxJenkins approach. International Journal of Forecasting, 8, $329-338$.

Pollard, J. H. (1987). Projection of age-specific mortality rates. Population Bulletin of the United Nations, 21-22, 55-69.

Pollard, J. H., \& Valkovics, E. J. (1992). The Gompertz distribution and its applications. Genus, 48, 15-27.

Preston, S. H., Heuveline, P., \& Guillot, M. (2001). Demography: Measuring and modeling population processes. Oxford: Blackwell.

Quesnel-Vallée, A., \& Morgan, S. P. (2003). Missing the target? Correspondence of fertility intentions and behavior in the U.S. Population Research and Policy Review, 22, 497-525.

Renshaw, A. E. (1991). Actuarial graduation practice and generalised linear and non-linear models. Journal of the Institute of Actuaries, 118, 295-312.

Renshaw, A. E., \& Haberman, S. (2000). Modelling for mortality reduction factors (actuarial research paper no. 127). London: Department of Actuarial Science and Statistics, City University.

Renshaw, A. E., \& Haberman, S. (2003a). Lee-Carter mortality forecasting with age-specific enhancement. Insurance: Mathematics and Economics, 33, 255-272.

Renshaw, A. E., \& Haberman, S. (2003b). On the forecasting of mortality reduction factors. Insurance: Mathematics and Economics, 32, 379-401.

Renshaw, A. E., \& Haberman, S. (2003c). Lee-Carter mortality forecasting: A parallel generalized linear modelling approach for England and Wales mortality projections. Applied Statistics, 51, 119-137.

Renshaw, A. E., Haberman, S., \& Hatzoupoulos, P. (1996). The modelling of recent mortality trends in United Kingdom male assured lives. British Actuarial Journal, 2, 449-477.

Rogers, A. (1975). Introduction to multiregional mathematical demography. New York: Wiley.

Rogers, A. (1986). Parameterized multistate population dynamics and projections. Journal of the American Statistical Association, $81,48-61$.

Rogers, A. (1988). Age patterns of elderly migration: An international comparison. Demography, 25, 355-370.

Rogers, A. (Ed.) (1995a). Population projections: Simple vs. complex models. Special issue of Mathematical Population Studies, Vol. 5(3).

Rogers, A. (1995b). Multiregional demography: Principles, methods, and extensions. London: John Wiley.

Rogers, A. (1995c). Population forecasting: Do simple models outperform complex models? Mathematical Population Studies, $5,187-202$.
Rogers, A., \& Castro, L. J. (1981). Model migration schedules. Research report 81-30. Laxenburg, Austria: International Institute for Applied Systems Analysis.

Rogers, A., Castro, L. J., \& Lea, M. (2005). Model migration schedules: Three alternative linear parameter estimation methods. Mathematical Population Studies, 12, 17-38.

Rogers, A., \& Gard, K. (1991). Applications of the Heligman/ Pollard model mortality schedule. Population Bulletin of the United Nations, 30, 79-105.

Rogers, A., \& Little, J. S. (1994). Parameterizing age patterns of demographic rates with the multiexponential model schedule. Mathematical Population Studies, 4, 175-195.

Rogers, A., \& Planck, F. (1983). Model: A general program for estimating parameterized model schedules of fertility, mortality, migration, and marital and labor force status transitions. Laxenburg, Austria: International Institute for Applied Systems Analysis.

Rogers, A., Raquillet, R., \& Castro, L. J. (1978). Model migration schedules and their applications. Environment and Planning, A, $10,475-502$.

Rogers, A., \& Watkins, J. (1987). General versus elderly interstate migration and population redistribution in the United States. Research on Aging, 9, 483-529.

Rogers, A., \& Woodward, J. A. (1991). Assessing state population projections with transparent multiregional demographic models. Population Research and Policy Review, 10, $1-26$.

Ryder, N. B. (1983). Cohort and period measures of changing fertility. In R. Bulatao, \& R. D. Lee (Eds.), Determinants of fertility in developing countries, vol. 2 (pp. 737-756). New York: Academic Press.

Ryder, N. B. (1990). What is going to happen to American fertility? Population and Development Review, 16, 433-454.

Sanderson, W. C. (1995). Predictability, complexity, and catastrophe in a collapsible model of population, development, and environmental interactions. Mathematical Population Studies, $5,259-279$.

Sanderson, W. C. (1999). Knowledge can improve forecasts: A review of selected socioeconomic population projection models. Frontiers of population forecasting. Supplement to Population and Development Review, vol. 24 (pp. 88-117). New York: Population Council.

Sanderson, W. C., \& Scherbov, S. (2005). Average remaining lifetimes can increase as human populations age. Nature, 435, 811-813.

Sanderson, W. C., Scherbov, S., O’Neill, B. C., \& Lutz, W. (2004). Conditional probabilistic population forecasting. International Statistical Review, 72, 157-166.

Siler, W. (1983). Parameters of mortality in human populations with widely varying life spans. Statistics in Medicine, 2, 373-380.

Sithole, T. Z., Haberman, S., \& Verrall, R. J. (2000). An investigation into parametric models for mortality projections, with applications to immediate annuitants' and life office pensioners' data. Insurance: Mathematics and Economics, 27, 285-312.

Sivamurthy, M. (1987). Principal components representation of ASFR: Model of fertility estimation and projection. $C D C$ research monograph number, 16 (pp. 655-693). Cairo Demographic Center. 
Smith, S. K. (1987). Tests of forecast accuracy and bias for county population projections. Journal of the American Statistical Association, 82, 991-1003.

Smith, S. K. (1997). Further thoughts on simplicity and complexity in population projection models. International Journal of Forecasting, 13, 557-565.

Smith, S. K., \& Sincich, T. (1990). On the relationship between length of base period and population forecast errors. Journal of the American Statistical Association, 85, 367-375.

Smith, S. K., \& Sincich, T. (1991). An empirical analysis of the effect of length of forecast horizon on population forecast errors. Demography, 28, 261-274.

Smith, S. K., \& Sincich, T. (1992). Evaluating the forecast accuracy and bias of alternative population projections for states. International Journal of Forecasting, 8, 495-508.

Sobotka, T. (2005). Childless societies? Trends and projections of childlessness in Europe and the United States. Paper presented at the Eurostat/ECE Joint Work Session on Demographic Projections, Vienna.

Stoto, M. A. (1983). The accuracy of population projections. Journal of the American Statistical Association, 78, 13-20.

Stoto, M. A. (1988). Dealing with uncertainty: Statistics for an aging population. The American Statistician, 42, 103-110.

Stoto, M. A., \& Durch, J. S. (1993). Forecasting survival, health, and disability: Report on a workshop. Population Development and Review, 19, 557-581.

Swanson, D. A., \& Tayman, J. (1995). Between a rock and a hard place: The evaluation of demographic forecasts. Population Research and Policy Review, 14, 233-249.

Sykes, Z. M. (1969). Some stochastic versions of the matrix model for population dynamics. Journal of the American Statistical Association, 44, 111-130.

Tabeau, E. (2001). A review of demographic forecasting models for mortality. In E. Tabeau, A. Van Den Berg Jeths, \& C. Heathcote (Eds.), Forecasting mortality in developed countries: Insights from a statistical, demographic and epidemiological perspective (pp. 1-32). Dordrecht: Kluwer Academic Publishers.

Tabeau, E., Ekamper, P., Huisman, C., \& Bosch, A. (2001). Predicting mortality from period, cohort or cause-specific trends: A study of four European countries. In E. Tabeau, A. Van Den Berg Jeths, \& C. Heathcote (Eds.), Forecasting mortality in developed countries: Insights from a statistical, demographic and epidemiological perspective (pp. 159-187). Dordrecht: Kluwer Academic Publishers.

Tabeau, E., Willekens, F., \& van Poppel, F. (2002). Parameterisation as a tool in analysing age, period and cohort effects on mortality: A case study of the Netherlands. In G. Wunsch, M. Mouchart, \& J. Duchene (Eds.), The life table: Modelling survival and death (pp. 141-169). Dordrecht, The Netherlands: Kluwer Academic Publishers.

Tayman, J., Schafer, E., \& Carter, L. (1998). The role of population size in the determination and prediction of population forecast errors: An evaluation using confidence intervals for subcounty areas. Population Research and Policy Review, 17, 1-20.

Tayman, J., \& Swanson, D. A. (1999). On the validity of MAPE as a measure of population forecast accuracy. Population Research and Policy Review, 18, 299-322.
Tayman, J., Swanson, D. A., \& Barr, C. F. (1999). In search of the ideal measure of accuracy for subnational demographic forecasts. Population Research and Policy Review, 18, 387-409.

Thatcher, A. R. (1999). The long-term pattern of adult mortality and the highest attained age. Journal of the Royal Statistical Society, Series A, Statistics in Society, 162, 5-43.

Thompson, P. A., Bell, W. R., Long, J. F., \& Miller, R. B. (1989). Multivariate time series projections of parameterized agespecific fertility rates. Journal of the American Statistical Association, 84, 689-699.

Trussell, J., \& Bloom, D. E. (1983). Estimating the co-variates of age at marriage and first birth. Population Studies, 37, 403-416.

Tuljapurkar, S. (1992). Stochastic population forecasts and their uses. International Journal of Forecasting, 8, 385-391.

Tuljapurkar, S. (1997). Taking the measure of uncertainty. Nature, $387,760-761$.

Tuljapurkar, S. (1998). Forecasting mortality change: Questions and assumptions. North American Actuarial Journal, 2, 127-134.

Tuljapurkar, S. (2005). Stochastic forecasts of mortality, population and pension systems. In N. Keilman (Ed.), Perspectives on mortality forecasting. Probabilistic models, vol. II (pp. 65-77). Stockholm: Swedish Social Insurance Agency.

Tuljapurkar, S., \& Boe, C. (1998). Mortality change and forecasting: How much and how little do we know? North American Actuarial Journal, 2, 13-47.

Tuljapurkar, S., \& Boe, C. (1999). Validation, probability-weighted priors, and information in stochastic forecasts. International Journal of Forecasting, 15, 259-271.

Tuljapurkar, S., \& Lee, R. D. (1997). Demographic uncertainty and the stable equivalent population. Mathematical and Computer Modelling, 26, 39-56.

Tuljapurkar, S., Lee, R. D., \& Li, Q. (2004). Random scenario forecasts versus stochastic forecasts. International Statistical Review, 72, 185-199.

Tuljapurkar, S., Li, N., \& Boe, C. (2000). A universal pattern of mortality decline in the G7 countries. Nature, 405, 789-792.

United Nations. (2000). Methodology of the United Nations population estimates and projections. World population prospects: The 1998 revision. Analytical report, vol. III (pp. 175-188). New York: United Nations.

United Nations (2001). Replacement Migration: Is it a solution to declining and ageing populations? (No. ST/ESA/SER.A/206). New York: United Nations.

United Nations. (2004). World population to 2300. New York: United Nations.

Van de Giessen, H. (1992). Using birth expectations information in national population forecasts. In N. Keilman, \& $\mathrm{H}$. Cruijsen (Eds.), National population forecasting in industrialized countries (pp. 223-241). Amsterdam: Swets and Zeitlinger.

Van Den Berg Jeths, A., Hoogenveen, R., De Hollander, G., \& Tabeau, E. (2001). A review of epidemiological approaches to forecasting mortality and morbidity. In E. Tabeau, A. Van Den Berg Jeths, \& C. Heathcote (Eds.), Forecasting mortality in developed countries: Insights from a statistical, demographic and epidemiological perspective (pp. 33-56). Dordrecht: Kluwer Academic Publishers. 
Van der Gaag, N., De Beer, J., \& Willekens, F. (2005). Combining micro and macro approaches in demographic forecasting. Paper presented at the Joint Eurostat-UNECE Work Session on Demographic Projections, Vienna. 21-23 September 2005.

Van Genugten, M., Hoogenveen, R., \& De Hollander, A. (2001). Incorporating risk factor epidemiology in mortality projections. In E. Tabeau, A. Van Den Berg Jeths, \& C. Heathcote (Eds.), Forecasting mortality in developed countries: Insights from a statistical, demographic and epidemiological perspective (pp. 189-204). Dordrecht: Kluwer Academic Publishers.

Van Hoorn, W., \& De Beer, J. (2001). Projecting mortality in population forecasts in the Netherlands. In E. Tabeau, A. Van Den Berg Jeths, \& C. Heathcote (Eds.), Forecasting mortality in developed countries: Insights from a statistical, demographic and epidemiological perspective (pp. 205-226). Dordrecht: Kluwer Academic Publishers.

Van Hoorn, W., \& Keilman, N. (1997). Birth expectations and their use in fertility forecasting (Eurostat Working Paper No. E4/ 1997-4). Luxemburg: Eurostat.

Van Imhoff, E., \& Post, W. (1998). Microsimulation method for population projections. Population: An English Selection, 10, $97-138$

Vaupel, J. W., \& Yashin, A. I. (1985). Heterogeneity's ruses: Some surprising effects of selection on population dynamics. The American Statistician, 39, 176-185.

Wachter, K. W. (1991). Elusive cycles: Are there dynamically possible Lee-Easterlin models for U.S. births? Population Studies, 45, 109-135.

Westoff, C. (1981). The validity of birth intentions: Evidence from US longitudinal studies. In G. E. Hendershot, \& P. J. Placek (Eds.), Predicting fertility (pp. 51-59). Lexington, MA: Lexington Books.

Willekens, F. J. (1990). Demographic forecasting; state-of-the-art and research needs. In C. A. Hazeu, \& G. A. B. Frinking (Eds.), Emerging issues in demographic research (pp. 9-75). Dordrecht: Elsevier Science.

Willekens, F. J. (1992). National population forecasting: State-ofthe-art and research needs. In N. Keilman, \& H. Cruijsen (Eds.), National population forecasting in industrialized countries (pp. 283-322). Amsterdam: Swets and Zeitlinger.

Willekens, F. J. (2001). Gompertz in context: The Gompertz and related distributions. In E. Tabeau, A. Van Den Berg Jeths, \& C. Heathcote (Eds.), Forecasting mortality in developed countries: Insights from a statistical, demographic and epidemiological perspective (pp. 105-126). Dordrecht: Kluwer Academic Publishers.

Willekens, F. J. (2005). Biographic forecasting: Bridging the micromacro gap in population forecasting. In A. Dharmalingam, \& I. Pool (Eds.), New Zealand population review, special issue on stochastic population projections, vol. 31 (pp. 77-124).

Willekens, F. J., \& Baydar, N. (1986). Age-period-cohort models for forecasting fertility (no. 45). The Hague: NIDI.

Willekens, F.J., De Beer, J., and Van der Gaag, N. (2005). MicMac: from demographic to biographic forecasting. Paper presented at the Joint Eurostat-UNECE Work Session on Demographic projections, Vienna. 21-23 September 2005.
Wilmoth, J. R. (1990). Variation in vital rates by age, period and cohort. Sociological Methodology, 20, 295-335.

Wilmoth, J. R. (1993). Computational methods for fitting and extrapolating the Lee-Carter model of mortality change (technical report). University of California, Berkeley: Department of Demography.

Wilmoth, J. R. (1995a). Are mortality projections always more pessimistic when disaggregated by cause of death? Mathematical Population Studies, 5, 293-319.

Wilmoth, J. R. (1995b). Are mortality rates falling at extremely high ages? An investigation based on a model proposed by Coale and Kisker. Population Studies, 49, 281-295.

Wilmoth, J. R. (1996). Mortality projections for Japan: A comparison of four methods. In G. Caselli, \& A. Lopez (Eds.), Health and mortality among elderly populations (pp. 266-287). New York: Oxford University Press.

Wilmoth, J. R. (2001). Age-period-cohort models in demography. In G. Caselli, J. Vallin, \& G. Wunsch (Eds.), Demographie: Analyse et synthese. La Dynamique des Populations, vol. I (pp. 379-397). Paris: INED.

Wilmoth, J. R. (2005). Some methodological issues in mortality projection, based on an analysis of the U.S. social security system. Genus, LXI, 179-212.

Wilson, T., \& Bell, M. (2004). Australia's uncertain demographic future. Demographic Research, 11, 195-234.

Wilson, T., \& Rees, P. (2005). Recent developments in population projection methodology: A review. Population, Space and Place, II, 337-360.

Wolf, D. A. (2004). Another variation on the Lee-Carter model. Paper presented at the Annual meeting of the Population Association of America, Boston.

Wong-Fupuy, C., \& Haberman, S. (2004). Projecting mortality trends: Recent developments in the United Kingdom and the United States. North American Actuarial Journal, 8, 56-83.

Yashin, A. I. (2001). Mortality models incorporating theoretical concepts of ageing. In E. Tabeau, A. Van Den Berg Jeths, \& C. Heathcote (Eds.), Forecasting mortality in developed countries: Insights from a statistical, demographic and epidemiological perspective (pp. 261-280). Dordrecht: Kluwer Academic Publishers.

Yashin, A. I., Iachine, I. A., \& Begun, A. S. (2000). Mortality modelling: A review. Mathematical Population Studies, 8, $305-332$.

Zaba, B. (1979). The four-parameter logit life table system. Population Studies, 33, 79-100.

Zaba, B. (1985). A parameterized procedure for projecting population. International Population Conference, Florence, vol. 4. (pp. 137-150). Liège: International Union for the Scientific Study of Population.

Zaba, B. (1987). The indirect estimation of migration: A critical review. International Migration Review, 21, 1395-1444.

Zeng, Y., Zhenglian, W., Zhongdong, M., \& Chunjun, C. (2000). A simple method for projecting or estimating $\alpha$ and $\beta$ : An extension of the Brass relational Gompertz fertility model. Population Research and Policy Review, 19, 525-549. 